Article

\title{
A New Hybrid Technique for Minimizing Power Losses in a Distribution System by Optimal Sizing and Siting of Distributed Generators with Network Reconfiguration
}

\author{
Mirna Fouad Abd El-salam ${ }^{1}$, Eman Beshr ${ }^{1, *}$ and Magdy B. Eteiba ${ }^{2}$ \\ 1 Electrical and Control Engineering Department, Arab Academy for Science, Technology, and Maritime \\ Transport, Sheraton Al Matar, P.O.2033 Elhorria, Cairo 11311, Egypt; mirnafouad@aast.edu \\ 2 The Faculty of Engineering, Fayoum University, Al Fayoum, Faiyum 63514, Egypt; meteiba@gmail.com \\ * Correspondence: beshre@aast.edu; Tel.: +20-1114153334
}

Received: 7 November 2018; Accepted: 26 November 2018; Published: 30 November 2018

\begin{abstract}
Transformations are taking place within the distribution systems to cope with the congestions and reliability concerns. This paper presents a new technique to efficiently minimize power losses within the distribution system by optimally sizing and placing distributed generators (DGs) while considering network reconfiguration. The proposed technique is a hybridization of two metaheuristic-based algorithms: Grey Wolf Optimizer (GWO) and Particle Swarm Optimizer (PSO), which solve the network reconfiguration problem by optimally installing different DG types (conventional and renewable-based). Case studies carried out showed the proposed hybrid technique outperformed each algorithm operating individually regarding both voltage profile and reduction in system losses. Case studies are carried to measure and compare the performance of the proposed technique on three different works: IEEE 33-bus, IEEE 69-bus radial distribution system, and an actual 78-bus distribution system located at Cairo, Egypt. The integration of renewable energy with the distribution network, such as photovoltaic (PV) arrays, is recommended since Cairo enjoys an excellent actual record of irradiance according to the PV map of Egypt.
\end{abstract}

Keywords: AC power flow (AC-PF); distributed generators (DGs); hybrid GWO-PSO; losses reduction; metaheuristic algorithms; renewable energy resources (RES); system reconfiguration; voltage profile

\section{Introduction}

Congestion of the distribution system is an issue that may be caused due to sudden increase in the load demand and an outage of transmission lines and generators. In order to solve this issue, several methods are used, such as distribution network reconfiguration (DNR) and optimal placement and sizing of distributed generators (DGs). Network reconfiguration is a method that deals with the uncertainty of loads by opening a few sectionalizing switches and closing a few tie switches. Optimal penetration of DGs has many advantages including improvement in the voltage profile, security, reliability, and minimization of transmission losses by installing DGs in proximity to the user. DGs are classified into two types: renewable energy resource (RES) DGs and non-RES DGs. On the one hand, some of the RES DGs are only capable of injecting active power such as photovoltaic cells and fuel cells (P-type) or injecting active and reactive power by adding smart inverters to them. Others are capable of injecting active power and consuming reactive power like induction generators of wind turbines ( $\mathrm{PQ}^{-}$-type). The main advantage of RES DGs is the minimization of the total cost, given that they are cheaper than conventional DGs, minimizing global warming and reducing system losses. 
On the other hand, some of the non-RES DGs are capable of injecting both active and reactive power such as combined combustion technology ( $\mathrm{PQ}^{+}$-type), the internal combustion engine and combined cycle-based DGs. Non-RES is characterized by minimizing active and reactive losses whereas their main disadvantage is that they have a small effect on the total generation cost reduction and lead to an increase in global warming. Several studies use each of the DGs placements in distribution networks and network reconfiguration separately to both minimize real power loss and improve the voltage stability of the power system. However, very few ones propose the network reconfiguration to be used in parallel with the DG locating and sizing for the maximum reduction of system losses. This work is a completion of work published in [1].

Later research studies develop optimization techniques, which are classified into meta-heuristic methods, heuristic methods, hybrid methods and analytical methods to solve single or multiple objective functions.

The metaheuristic, heuristic, and hybrid methods are used to determine the optimal allocation and sizing of DGs only. Some of these methods are used to solve multi-objective function, such as Moth Flame Optimization (MFO) [2] and the GWO algorithm [3-5]. Others, such as the PSO algorithm [6,7], Artificial Bee Colony algorithm (ABC) [8,9], and Bat Algorithm (BA) [10] are used to minimize power loss. Optimal DG Placement (ODGP) and sizing are presented using four selected heuristic algorithms: Cuckoo Search Algorithm (CSA), Gravitational Search Algorithm (GSA), Genetic Algorithm (GA), and Particle Swarm Optimization (PSO) so as to minimize real power loss [11]. The Simulated Annealing (SA) algorithm and Forward-Backward Sweep (FW/BW) algorithm are used for determining the optimal placement of multiple distributed generations in the radial distribution system in order to solve multi-objective function [12].

The analytical methods presented in [13] are also used for DGs installment to reduce losses. It includes loss sensitivity analysis and voltage sensitivity analysis to find the optimal allocation and size for single DG. It considers 0.5 MVA incremental steps to a maximum 4 MVA at different power factors. Two different sensitivity analyses used for single DG placement [14]. The Efficient Analytical (EA) method is used for multiple DGs placement [15]. In order to combine the advantages and avoid the disadvantages of the latter methods, a hybridization between the metaheuristic method and the analytical approach has been implemented in [16] which uses the Loss Sensitivity Factor (LSF) and Back Tracking Search Optimization Algorithm (BSOA).

Other metaheuristic and heuristic methods are used for system reconfiguration only and they include Discrete Artificial Bee Colony (DABC) algorithm, which is used to maximize system load ability [17]; the Cuckoo Search Algorithm (CSA) which is used to minimize active power loss and maximize voltage magnitude [18]; the Bacterial Foraging Optimization Algorithm (BFOA), which is used to minimize real power loss [19]; and Fuzzy multi-objective used for real-power loss reduction [20]. Authors in [21] have used two algorithms namely Fuzzy Mutated Genetic Algorithm (FMGA) and Evolutionary Programming (EP) to reconfigure the Radial Distribution System (RDS) by minimizing the real and reactive power losses and improving the power quality at the same time. PSO and GA using graph theory are applied to find the radial configuration for two different distribution networks in order to minimize losses and improve voltage profile [22]. Improved Binary Particle Swarm Optimization is used to reconfigure system with capacitor placement for power loss reduction of distribution system [23]. Heuristic algorithm and optimal power flow (OPF) have been considerably enhanced to find out optimal system reconfiguration for minimizing total reconfiguration cost [24].

Some studies use different methods to solve the network reconfiguration problem in parallel with the DG locating and sizing. Reference [25] proposes Binary Particle Swarm Optimization (BPSO) for system reconfiguration, Loss Sensitivity Factor (LSF) for finding DG optimal location, and Harmony Search Algorithm (HSA) for DG sizing. Reference [26] presents Mixed-Integer Second-Order Cone Programming (SOCP) to determine network reconfiguration, DG locating, and DG sizing problems. Reference [27] maximizes system load ability by solving the above mentioned three problems based on the Discrete Artificial Bee Colony (DABC) algorithm. Reference [28] solved the three problems 
based on Genetic Algorithm (GA). Reference [29] solves network reconfiguration and DG sizing the based on Harmony Search Algorithm (HSA) and relies on sensitivity analysis to determine DG units allocation. Reference [30] suggests the solution of reconfiguration and DG sizing based on Fire Work Algorithm (FWA) and DGs allocation based on Voltage Stability Index (VSI). Reference [31] proposes a system reconfiguration problem of an unbalanced distribution network using Fuzzy Firefly algorithm, where the loss sensitivity factor is used to get the appropriate location of distribution generator where Bacterial Foraging optimization Algorithm (BFOA) is used to find the rating of the DGs. In [32] the authors developed a modified Teaching Learning Based Optimization technique (TLBO) to reconfigure the distribution network and find the optimal sizing and location of DGs in order to minimize the total system loss. In [33] the authors proposed a technique to solve the DG location and size problem, which they named Meta-Heuristic Algorithms (MHA) and proposed a Binary Particle Swarm Optimization algorithm (BPSO) for solving network reconfiguration, however it cannot be used to solve the DG sizing problem.

The authors in [34] used Selective Particle Swarm Optimization (SPSO) to solve the network reconfiguration problem and sensitivity analysis method to determine optimal size and location. In [35] the authors developed an analytical method which is Voltage Limitation Index (VLI) to solve network reconfiguration as well as DG sizing, and siting. In [36] the authors proposed the Modified Plant Growth Simulation Algorithm (MPGSA) to solve reconfiguration and DG sizing. Moreover Loss Sensitivity Factor (LSF) was used to find the optimal location of DG. In [37] and [38] the authors used PSO to solve reconfiguration and DG sizing while the locations of the DGs are fixed at the buses with the lowest voltage profile. Furthermore in [39], utilizing power demand and DG profile data are found using the Fuzzy C-Means (FCM) clustering algorithm. In addition, optimum system configurations are found using a GA to minimize annual energy losses.

Many researchers use metaheuristic or heuristic methods to determine the optimal allocation and sizing of DGs using the single optimization technique to solve both location and size of DG, however, it may not reach the optimal solution especially in large systems. Other researchers use sensitivity analysis to find constant placement for DG units to minimize the number of iterations but do not reach the optimal solution as well.

This paper proposes a new hybrid GWO-PSO technique to solve system reconfiguration, DGs sizing and DGs sitting. This hybridization eliminates the disadvantages and emphasizes the advantages of both techniques simultaneously and it proves it suitability for large distribution system to reach the optimal solution. In the present investigation, minimizing the number of iterations is not considered as the most important issue compared with the vital concern that the system would be able to withstand the increase of load demand requirements. This paper uses this hybridization to find not only the optimal sizing and siting of DGs but also the optimal reconfiguration of the system. Moreover, this paper injects active and reactive power into the system unlike most of the studies that inject active power only. To check the validity of the proposed technique some of the results will be compared to a reference that uses sensitivity analysis to identify DG allocation and use one of the optimization methods to find size of the DG.

The remainder of this paper is organized as follows: problem formulation is given in Section 2. The hybrid GWO-PSO algorithm is proposed in Section 3. The hybrid GWO-PSO optimizer implementation for system reconfiguration and DG allocation is proposed in Section 4. The numerical results are discussed in Section 5. Concluding remarks are presented in Section 6.

\section{Problem Formulation}

The problem involves minimizing power loss based on system reconfiguration, DGs sizing and sitting. Eight case studies will be illustrated to reach the maximum reduction of losses. Using real power loss as an objective function will not only reduce real power losses but will also reduce reactive power losses and improve the voltage profile of the system. This problem will be solved using the proposed hybrid GWO-PSO technique. 


\subsection{Objective Function}

The total losses in the line section connecting buses $i$ and $i+1$ are derived in [40] as follows:

$$
\begin{gathered}
\text { Losses }=\frac{\left|V_{i}-V_{i+1}\right|^{2}}{R_{i}-j X_{i}}, \\
P_{\text {Loss }(i, i+1)}=\text { Real } \mid \text { Losses } \mid, \\
Q_{\text {Loss }(i, i+1)}=\text { Imag } \mid \text { Losses } \mid,
\end{gathered}
$$

where $V_{i}$ is voltage at bus $i, R_{i}$, and $X_{i}$ are resistance and reactance of the line section between buses $i$ and $i+1$ respectively, and $P_{\operatorname{Loss}(i, i+1)}$ and $Q_{\operatorname{Loss}(i, i+1)}$ are real and reactive power loss from buses $i$ to $i+1$.

\subsection{Constraints}

The problem inequality constraints are given as follows:

1. The voltage at each bus should be within specific limits:

$$
V_{\min } \leq\left|V_{i}\right| \leq V_{\max }
$$

where $V_{\max }$ and $V_{\min }$ are maximum and minimum bus voltage, respectively.

2. Current at each line should be within specific limits:

$$
\left|I_{i, i+1}\right| \leq\left|I_{i, i+1, \max }\right|
$$

where $I_{i, i+1}$ is the current in the line section between buses $i$ and $i+1$, and $I_{i, i+1, \max }$ is the current's maximum limit of the line between buses $i$ and $i+1$.

3. Total generated power at each bus should be less than the summation of total load and total losses:

$$
\sum_{i=1}^{n} P_{D i} \leq \sum_{i=1}^{n}\left(P_{i}+P_{\operatorname{Loss}(i, i+1)}\right)
$$

where $P_{i}$ is real power flowing out of bus $i$, and $P_{D i}$ is real power supplied by DG at bus $i$.

4. Size of DG units should be within specific limits:

$$
P_{D i, \min } \leq P_{D i} \leq P_{D i, \max }
$$

where $P_{D i, \max }$ and $P_{D i, \min }$ are maximum and minimum power supplied by DG, respectively.

5. The following balance equations [41] must be applied at each bus:

$$
\begin{gathered}
P_{i+1}=P_{i}-P_{L o s s, i}-P_{L i+1}=P_{i}-\frac{R_{i}}{\left|V_{i}\right|^{2}}\left\{P_{i}^{2}+\left(Q_{i}+Y_{i}\left|V_{i}\right|^{2}\right)^{2}\right\}-P_{L i+1}, \\
Q_{i+1}=Q_{i}-Q_{L o s s, i}-Q_{L i+1}=Q_{i}-\frac{X_{i}}{\left|V_{i}\right|^{2}}\left\{P_{i}^{2}+\left(Q_{i}+Y_{i 1}\left|V_{i}\right|^{2}\right)^{2}\right\}-Y_{i 1}\left|V_{i}\right|^{2}-Y_{i 2}\left|V_{i+1}\right|^{2}-Q_{L i+1}, \\
\left|V_{i+1}\right|^{2}=\left|V_{i}\right|^{2}+\frac{R_{i}^{2}+X_{i}^{2}}{\left|V_{i}\right|^{2}}\left(P_{i}^{2}+Q_{i}^{\prime 2}\right)-2\left(R_{i} P_{i}+X_{i} Q_{i}\right)=\left|V_{i}\right|^{2}+\frac{R_{i}^{2}+X_{i}^{2}}{\left|V_{i}\right|^{2}}\left(P_{i}^{2}+\left(Q_{i}+Y_{i}\left|V_{i}\right|^{2}\right)^{2}\right) \\
-2\left(R_{i} P_{i}+X_{i}\left(Q_{i}+Y_{i}\left|V_{i}\right|^{2}\right)\right),
\end{gathered}
$$

where $Q_{i}$ is the reactive power flowing out of bus $i, Y_{i}$ is shunt admittance at bus $i$, and $P_{L i+1}$ and $Q_{L i+1}$ are the real and reactive load power at bus $i+1$. 


\subsection{Power Loss Using System Reconfiguration}

The network reconfiguration is used to reduce system losses and to handle the system during any emergencies such as supplying loads during faults. The solution to the reconfiguration problem is to divide the system into five loops formed by each tie switch. $P^{\prime}$, Loss is the summation of all real power losses after reconfiguration:

$$
P^{\prime} T_{, \text {Loss }}=\sum_{i=1}^{n} P^{\prime} \operatorname{Loss}(i, i+1)
$$

\subsection{Power Loss Using DG Installation}

Distributed generators optimal allocation and sizing will postpone the system upgrade, and shave peak demand. The real power loss when a DG is installed at any location in the system is given by:

$$
P_{D G, \text { Loss }}=\frac{R_{i}}{V_{i}^{2}}\left(P_{i}^{2}+Q_{i}^{2}\right)+\frac{R_{i}}{V_{i}^{2}}\left(P_{D}^{2}+Q_{D}^{2}-2 P_{i} P_{D}-2 Q_{i} Q_{D}\right)\left(\frac{D}{L}\right),
$$

where $Q_{i}$ is the reactive power flowing out of bus $i, P_{D}$, and $Q_{D}$ are the real and reactive power supplied by the DG, respectively, $D$ is the distance from the source to DG bus location in $\mathrm{km}$, and $L$ is the total length of the feeder from source to bus.

\section{The Hybrid GWO-PSO Optimizer}

The system reconfiguration problem consists of discrete line numbers while the DG allocation problem consists of discrete bus numbers while the DG unit capacities problem is limited by system constraints. Instead of relying on sensitivity analysis to find the optimal allocation of DG units, a code will be formulated to search for an optimal reconfiguration, DG allocation, and capacity at the same time. Due to the nature of the nonlinear behavior of our problem, running GWO or PSO optimizers particularly in large systems, will not lead to the same results at each run and may not reach the optimal solution. Using the proposed hybridization technique eventually will solve this problem and the same optimal solution will be obtained at each run. Figure 1 shows a flow chart with the main steps of the hybrid GWO-PSO optimizer.

\subsection{The Grey Wolf Optimizer (GWO)}

The Grey Wolf Optimizer (GWO) is a meta-heuristic based optimization technique presented by Mirjalili and Lewis in 2014 [42]. The grey wolves prefer to follow a social strict dominant hierarchy level, which decreases from $\alpha$ to $\omega$ as shown in Figure 2. Alphas $(\alpha)$ are the leaders (males or females). Alphas $(\alpha)$ and betas $(\beta)$ are at the first and second highest levels of the hierarchy. Delta $(\delta)$ wolves have to follow to alphas and betas. The lowest level gray wolf is omega $(\omega)$. The mathematical formulation steps are (i) social hierarchy of GWO, (ii) encircling prey, and (iii) hunting prey. 


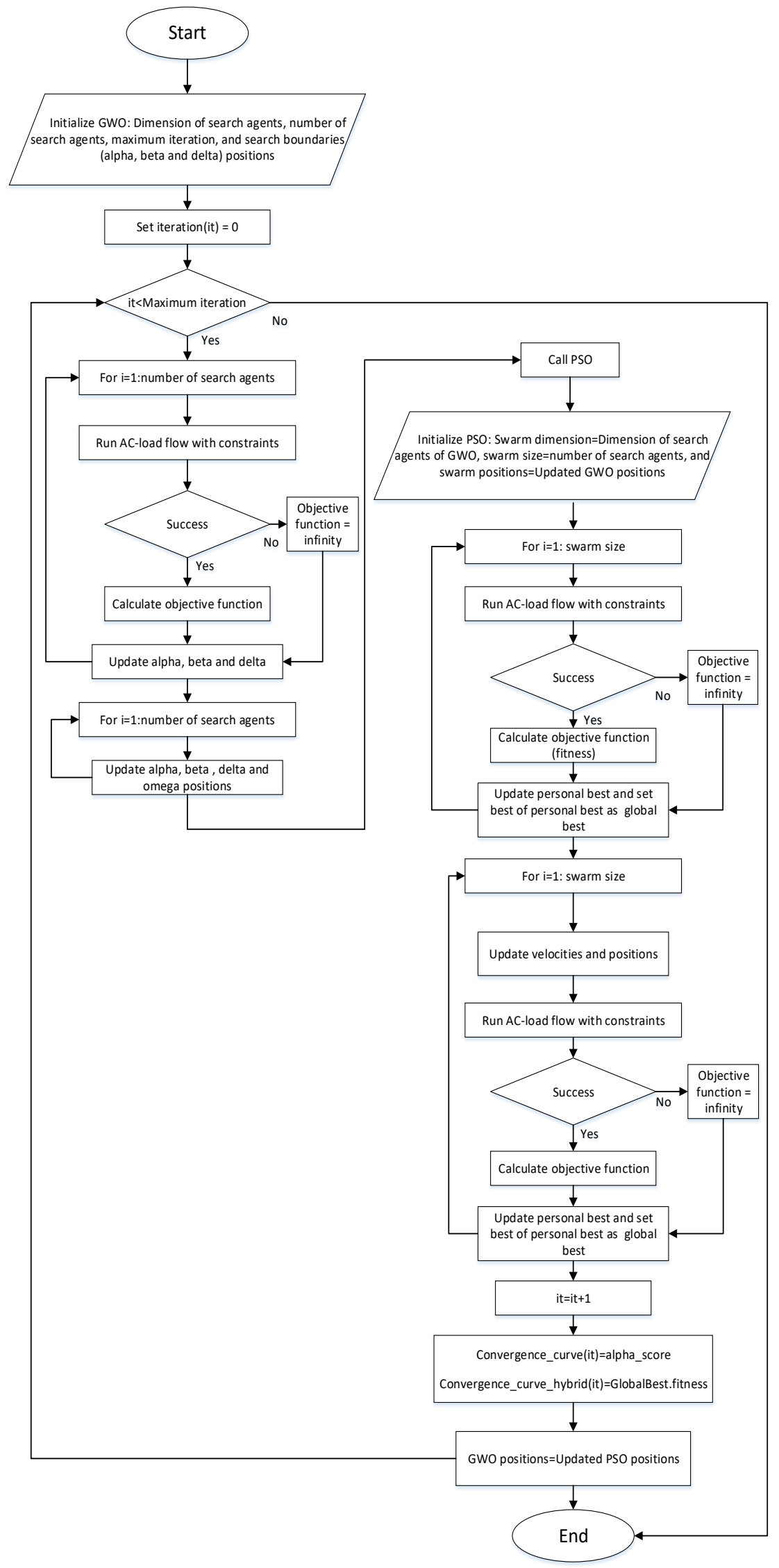

Figure 1. Flow chart of the hybrid GWO-PSO. 


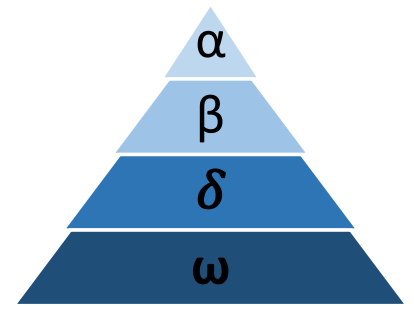

Figure 2. Hierarchy of grey wolf.

\section{Social Hierarchy of GWO}

$\alpha$ and $\beta$ are considered the first and second best solutions, respectively, whereas $\delta$ is considered to be the third best solution and $\omega$ wolves are considered to be the remaining of the solutions.

2. Encircling Prey

First, the grey wolves encircle the prey. In [42] the encircling procedure is given as follows:

$$
\begin{gathered}
\vec{D}=\left|\vec{C} \cdot \vec{X}_{p}(t)-\vec{X}(t)\right|, \\
\vec{X}(t+1)=\vec{X}_{p}(t)-\vec{A} \cdot \vec{D},
\end{gathered}
$$

where $t$ is the iteration number, $\vec{A}$ and $\vec{C}$ are coefficient vectors, $\vec{X}_{p}$ indicates the position vector of the prey, and $\vec{X}$ is the position vector of the grey wolf.

$\vec{A}$ and $\vec{C}$ vectors are calculated as follows:

$$
\begin{gathered}
\vec{A}=2 \vec{a} \cdot \vec{r}_{1}-\vec{a}, \\
\vec{C}=2 \cdot \vec{r}_{2},
\end{gathered}
$$

3. Hunting

Following the prey encircling process, the hunting process is simulated mathematically by considering that $\alpha, \beta$, and $\delta$ have better information about the prey's position. The prey is supposed to be the objective function. $\alpha, \beta$, and $\delta$ are the three best solutions so far so as to reach the optimal solution of the objective function. The $\omega$ wolves solutions will update their location according to the $\alpha$, $\beta$, and $\delta$ locations. The hunting procedure is given in [42] as follows:

$$
\begin{gathered}
\vec{D}_{\alpha}=\left|\overrightarrow{\mathrm{C}}_{1} \cdot \overrightarrow{\mathrm{X}}_{\alpha}-\overrightarrow{\mathrm{X}}\right|, \overrightarrow{\mathrm{D}}_{\beta}=\left|\overrightarrow{\mathrm{C}}_{2} \cdot \overrightarrow{\mathrm{X}}_{\beta}-\overrightarrow{\mathrm{X}}\right|, \overrightarrow{\mathrm{D}}_{\delta}=\left|\overrightarrow{\mathrm{C}}_{3} \cdot \overrightarrow{\mathrm{X}}_{\delta}-\overrightarrow{\mathrm{X}}\right| \\
\overrightarrow{\mathrm{X}}_{1}=\overrightarrow{\mathrm{X}}_{\alpha}-\overrightarrow{\mathrm{A}}_{1} \cdot\left(\overrightarrow{\mathrm{D}}_{\alpha}\right), \overrightarrow{\mathrm{X}}_{2}=\overrightarrow{\mathrm{X}}_{\beta}-\overrightarrow{\mathrm{A}}_{2} \cdot\left(\overrightarrow{\mathrm{D}}_{\beta}\right), \overrightarrow{\mathrm{X}}_{3}=\overrightarrow{\mathrm{X}}_{\delta}-\overrightarrow{\mathrm{A}}_{3} \cdot\left(\overrightarrow{\mathrm{D}}_{\delta}\right), \\
\overrightarrow{\mathrm{X}}(\mathrm{t}+1)=\frac{\overrightarrow{\mathrm{X}}_{1}+\overrightarrow{\mathrm{X}}_{2}+\overrightarrow{\mathrm{X}}_{3}}{3}
\end{gathered}
$$

\subsection{The Particle Swarm Optimizer (PSO)}

The Particle Swarm Optimizer (PSO) is a meta-heuristic-based optimization technique presented by James Kennedy and Russell Eberhart in 1995 [43]. The fundamental idea of PSO is that a group of particles is moving in the search space looking for the food or best solution mathematically. Each particle has a position and velocity vector. Figure 3 shows how the particles update their movements depending on their experiences, and personal and global best particles. The updating procedure of the particle position is given in [43] as follows: 


$$
\begin{gathered}
\overrightarrow{\mathrm{V}}_{i}(\mathrm{k}+1)=W \cdot \overrightarrow{\mathrm{V}}_{i}(\mathrm{k})+s_{1} r_{1} \cdot\left(\overrightarrow{\mathrm{P}}_{i}(\mathrm{k})-\overrightarrow{\mathrm{Y}}_{i}(\mathrm{k})\right)+s_{2} r_{2} \cdot\left(\overrightarrow{\mathrm{G}}(\mathrm{k})-\overrightarrow{\mathrm{Y}}_{i}(\mathrm{k})\right), \\
\overrightarrow{\mathrm{Y}}_{i}(\mathrm{k}+1)=\overrightarrow{\mathrm{Y}}_{i}(\mathrm{k})+\overrightarrow{\mathrm{V}}_{i}(\mathrm{k}+1),
\end{gathered}
$$

where $\mathrm{t}$ is the iteration number, $s_{1}$ and $s_{2}$ are the weighting factors, $r_{1}$ and $r_{2}$ are random numbers between 0 and $1, W$ indicates the weighting function, $\overrightarrow{\mathrm{V}}_{i}(\mathrm{k})$ is particle $i$ velocity at iteration $\mathrm{k}$, $\overrightarrow{\mathrm{V}}_{i}(\mathrm{k}+1)$ indicates the updated velocity of particle $i, \overrightarrow{\mathrm{Y}}_{i}(\mathrm{k})$ is particle $i$ position at iteration $\mathrm{k}, \overrightarrow{\mathrm{Y}}_{i}(\mathrm{k}+1)$ indicates the updated position of particle $i, \overrightarrow{\mathrm{P}}_{i}(\mathrm{k})$ is the personal best particle $i$, and $\overrightarrow{\mathrm{G}}(\mathrm{k})$ is the global best particle.

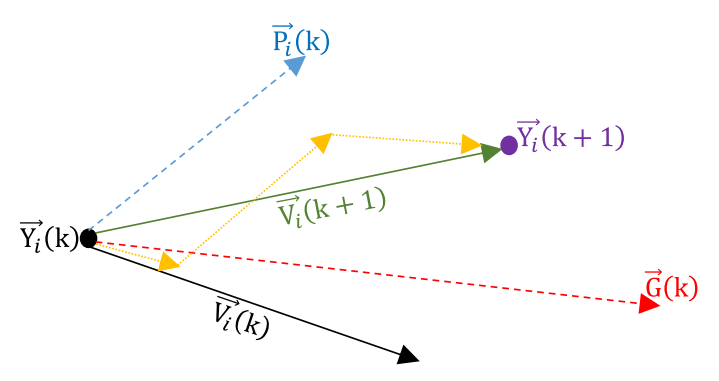

Figure 3. Search point modification by PSO.

\section{The Hybrid GWO-PSO Optimizer Implementation for System Reconfiguration and DG Allocation}

System reconfiguration and DG units' allocation in appropriate places reduce system losses, improve the system voltage profile, and reduce distribution lines overloading. The problem control variables are the system reconfiguration, DGs allocation, and DGs capacities, which control the fitness function. The complexity of solving those three variables in parallel lies in the fact that they have been solved them separately using several optimization techniques or using sensitivity analysis with optimization techniques. In the present study, these three problems are dealt with simultaneously by using the hybrid GWO-PSO technique.

The Hybrid GWO-PSO technique can be explained in the following steps:

Step 1: Set number of iterations.

Step 2: The Set an initial random population of search agents.

Step 3: Run GWO optimizer.

Step 4: pass the minimized searching space points to PSO optimizer as starting points.

Step 5: Run PSO optimizer.

Step 6: Pass these updated new searching space points back to GWO optimizer.

Step 7: Update the iteration counter.

Step 8: If the stopping criteria are satisfied go to step 9, else go to step 3.

Step 9: Stop. The global best particle is the optimal solution of the Hybrid GWO-PSO optimizer.

Simple numerical example for the hybrid GWO-PSO: (Scenario 8 for the 33-bus test system)

Step 1: Set number of iterations $=1$.

Step 2: Set an initial random population of search agents $=50$.

Step 3: Run GWO optimizer:

Best solution of GWO at the first iteration: (alpha wolf)

Real Power loss (objective function): 48.70 (kw)

Reconfigured lines: $\left(\begin{array}{lllll}27 & 4 & 21 & 14 & 17\end{array}\right)$

DGs locations: $\left(\begin{array}{lll}9 & 23 & 29\end{array}\right)$

DGs sizes (MW): $\quad\left(\begin{array}{llll}0.6889 & 1.5610 & 1.3506\end{array}\right)$ 
DGs sizes (MVar): $\quad\left(\begin{array}{lll}0.01343 & 1.2043 & 0.7735\end{array}\right)$

Step 4: pass the minimized searching space points to PSO optimizer as starting points.

Step 5: Run the PSO optimizer.

Best solution of PSO at the first iteration: (Global Best)

Real Power loss (objective function): $31.025(\mathrm{kw})$

Reconfigured lines: $\left(\begin{array}{lllll}27 & 3 & 10 & 12 & 15\end{array}\right)$

DGs locations: $\left(\begin{array}{lll}7 & 30 & 22\end{array}\right)$

DGs sizes (MW): $\quad\left(\begin{array}{lll}0.8558 & 1.5132 & 0.35148\end{array}\right)$

DGs sizes (MVar): $\quad\left(\begin{array}{lll}0.3217 & 1.8330 & 0.9405\end{array}\right)$

Step 6: Stop. The global best particle is the optimal solution of the hybrid GWO-PSO optimizer.

The program will update the number of iterations, and proceed as indicated in the above section until it reaches the optimal solution.

The optimization parameters of GWO, PSO, and GWO-PSO are listed below:

- The GWO parameters are a, $\mathrm{r}_{1}, \mathrm{r}_{2}, \mathrm{~A}$, and C. $\mathrm{r}_{1}$ and $\mathrm{r}_{2}$ are random numbers between zero and one. The parameter "a" is decreased linearly from 2 to zero. The A and C parameters of the GWO are calculated using Equations (15) and (16).

- The PSO parameters are inertia weight $(\mathrm{w})$ is set to be one, inertia weight damping ratio $\left(\mathrm{W}_{\mathrm{d}},\right)$ is set to be $0.99, \mathrm{~s}_{1}$, and $\mathrm{s}_{2}$ are set to 1.5 and 2 , respectively.

- The GWO-PSO hybridization operates using both GWO and PSO sequentially within each iteration using the above mentioned parameters of each technique. As for the rest of techniques: FWA, HAS, GA, and RGA their parameters were not used in the model, results published in [30] were used for comparison purposes.

Eight scenarios are considered to demonstrate the performance of the proposed technique with two different DG types:

1. Scenario 1: Base case which is basically a power flow solution of the problem.

2. Scenario 2: System reconfiguration.

3. Scenario 3: P-type (solar PV) DGs installations before reconfiguration.

4. Scenario 4: P type (solar PV) DGs installations after reconfiguration.

5. Scenario 5: P-type (solar PV) DGs installations while reconfiguration.

6. Scenario 6: $\mathrm{PQ}^{+}$-type (conventional combustion turbine) DGs installations before reconfiguration.

7. Scenario 7: $\mathrm{PQ}^{+}$-type (conventional combustion turbine) DGs installations after reconfiguration.

8. Scenario 8: $\mathrm{PQ}^{+}$-type (conventional combustion turbine) DGs installations while reconfiguration.

The solution vector $\mathrm{V}$ for the hybrid GWO-PSO technique to solve scenarios 2 to 8 is given below:

$$
\begin{aligned}
& \mathrm{V}=\{\underbrace{\mathrm{OS}^{1} \mathrm{OS}^{2} \mathrm{OS}^{3} \mathrm{OS}^{4} \mathrm{OS}^{5}}_{\text {reconfiguration }}\}, \\
& \mathrm{V}=\{\underbrace{\mathrm{L}^{1} \mathrm{~L}^{2} \mathrm{~L}^{3}}_{\text {DGs locationsDGs sizies of } \mathrm{p}+} \underbrace{\mathrm{S}^{1} \mathrm{~S}^{2} \mathrm{~S}^{3}}\}, \\
& \mathrm{V}=\{\underbrace{\mathrm{OS}^{1} \mathrm{OS}^{2} \mathrm{OS}^{3} \mathrm{OS}^{4} \mathrm{OS}}_{\text {reconfiguration }} \underbrace{\mathrm{L}^{1} \mathrm{~L}^{2} \mathrm{~L}^{3}}_{\text {DGs locationsDGs sizies of } \mathrm{p}+} \underbrace{\mathrm{S}^{1} \mathrm{~S}^{2} \mathrm{~S}^{3}}\},
\end{aligned}
$$




$$
\begin{aligned}
& V=\{\underbrace{L^{1} L^{2} L^{3}}_{\text {DGs locationsDGs sizies of } p+\text { DGs sizies of } Q+} \underbrace{S^{1} S^{2} S^{3}} \underbrace{S^{4} S^{5} S^{6}}\} \\
& \mathrm{V}=\{\underbrace{\mathrm{OS}^{1} \mathrm{OS}^{2} \mathrm{OS}^{3} \mathrm{OS}^{4} \mathrm{OS}}_{\text {reconfiguration }} \underbrace{\mathrm{L}^{1} \mathrm{~L}^{2} \mathrm{~L}^{3}}_{\text {DGs locationsDGs sizies of } \mathrm{p}+\text { DGs sizies of } \mathrm{Q}+} \underbrace{S^{1} \mathrm{~S}^{2} \mathrm{~S}^{3}} \underbrace{S^{4} \mathrm{~S}^{5} \mathrm{~S}^{6}}\}
\end{aligned}
$$

where $\mathrm{OS}^{1}, \mathrm{OS}^{2}, \mathrm{OS}^{3}, \mathrm{OS}^{4}$, and $\mathrm{OS}^{5}$ are five opened switches corresponding to $69,70,71,72$, and 73 tie switches. $\mathrm{L}^{1}, \mathrm{~L}^{2}$, and $\mathrm{L}^{3}$ are locations of DG units. $\mathrm{S}^{1}, \mathrm{~S}^{2}$, and $\mathrm{S}^{3}$ are sizes of DG units in MW. $\mathrm{S}^{4}, \mathrm{~S}^{5}$, and $S^{6}$ are sizes of DG units in MVar.

Equation (22) is used to find the solution vector of scenario 2 similarly; Equation (23) is used to find the solution vector of scenarios 3 and 4 . Equation (24) is used to find the solution vector of scenario 5; Equation (25) is used to find the solution vector of scenarios 6 and 7. Finally, Equation (26) is used to find the solution vector of scenario 8 .

All the parameters of the hybrid PSO-GWO remain the same during all scenarios, what differs is the vector ' $\mathrm{V}$ ' and it is modified according to the scenarios. The vector ' $\mathrm{V}$ ' is used within each scenario as presented from Equations (22)-(26). Equation (22) vector ' $V$ ' is used for system reconfiguration by selecting the best reconfigured switches to be opened in order to find the optimal solution. Equation (23) is used to solve scenarios 3 and 4, finding the optimal allocation and size for the three DG units before and after reconfiguration. Equation (24) is used to solve vector ' $V$ ' for scenario 5 to obtain the system reconfiguration and to find the optimal allocation and sizing of three DG units (case of DGs inject active power only). Equation (25) is used to solve scenarios 6 and 7 to find the optimal allocation and size for three DG units which inject active and reactive power. Finally, equation 26 is used for solving scenario 8 by merging all the above mentioned scenarios. The solution is to find 14 optimal points at the search space classified as five points for system reconfiguration, three points for DG locations, and six points for DG size (three points to find active power and another three for reactive power size).

\section{Result and Discussions}

In order to examine the validity of the proposed method in solving DG units' installation and network reconfiguration using the hybrid GWO-PSO, it is tested on two IEEE standard radial distribution systems (33-bus, 69-bus) and a 78-bus real distribution system in 6th October City, Egypt. The results are compared with those of GWO, PSO, and [30]. It is proved that there is no improvement in loss reduction percentage when DG locations are more than three units in Table 1. The number of DGs in each bus is limited to one. Most of the previous studies focused on the injection of active power only. In this paper, the effect of active and reactive power injection of DG units is studied.

All scenarios are programmed in MATLAB, and simulations are carried on a personal computer with Core i7 processor, $2.8 \mathrm{GHz}, 16 \mathrm{~GB}$ RAM.

Table 1. Different penetrations of DG units for a 69-bus system.

\begin{tabular}{ccc}
\hline Scenarios & \multicolumn{2}{c}{ Proposed Hybrid GWO-PSO } \\
\hline Base case & P loss (KW) & 224.9295 \\
\hline & DG size in MW (bus) & $1.87262(61)$ \\
One DG & P loss (KW) & 83.1679 \\
& reduction\% & 63.02 \\
\hline & DG size in MW (bus) & $1.7817(61), 0.53114(17)$ \\
Two DGs & P loss (KW) & 71.6356 \\
& reduction $\%$ & 68.15 \\
\hline
\end{tabular}


Table 1. Cont.

\begin{tabular}{ccc}
\hline Scenarios & \multicolumn{2}{c}{ Proposed Hybrid GWO-PSO } \\
\hline \multirow{3}{*}{ Three DGs } & DG size in MW (bus) & $0.5271(11), 1.7189(61), 0.3799(18)$ \\
& P loss (KW) & 69.3873 \\
& reduction $\%$ & 69.15 \\
\hline \multirow{2}{*}{ Four DGs } & DG size in MW (bus) & $0.4055(61), 0.3121(12), 0.1554(21), 0.0806(2)$ \\
& P loss (KW) & 71.8322 \\
& reduction $\%$ & 68.064 \\
\hline
\end{tabular}

For all test systems, the minimum and maximum voltage constraints are set at 0.9 p.u. and 1.1 p.u. respectively, and the substation voltage is 1 p.u. Voltage decreases from the source to the end nodes. The voltage profile is improved by adding DG units to the bus to cover part of the load, sequentially, reducing flowing current and line losses.

\subsection{IEEE 33-Bus Test System}

This system base configuration has 1-32 sectionalized switches normally closed and switches from 33-37 tie switches are normally opened. There are five loops formed by the five tie switches of the system. Tie switches are closed during an emergency case, such as faults, to cover unsupplied loads or to reduce system losses. The total real and reactive power loads are 3.715 MW and 2.3 MVAR respectively. The system base capacity is $100 \mathrm{MVA}$ and base voltage is $12.66 \mathrm{KV}$. The limits of real and reactive power injected by DGs are 0 to $2 \mathrm{MW}$ and 0 to 2 MVAR, respectively. The comparison between the results using the hybrid GWO-PSO and the individual use of GWO and PSO all scenarios are simulated with GWO and PSO results are provided in Tables 2 and 3. The population size is 50 in all techniques and scenarios. It can be observed from the below tables that the proposed new hybrid technique yields the lowest iteration numbers in all of the scenarios. The optimal candidate location using two DG types for scenario 3 to 8 are highlighted in Tables 2 and 3. It can also be observed from Tables 2 and 3 that the base case power loss is $202.67 \mathrm{~kW}$, which is reduced to 8.9162 using scenario 8 with percentage reduction of $95.60 \%$. In Figure 4, Scenario 7 shows that power loss for the $\mathrm{PQ}^{+}$type DG installation after reconfiguration is not less than DG installation before reconfiguration. Power loss reduction for scenario 8 is higher than any other scenario. From Figure 5, base case reactive loss is $135.141 \mathrm{kVar}$, which is reduced to $102.305,49.3921,44.2868,38.7201,9.6926,14.8282$, and 7.4668 for scenarios $2,3,4,5,6,7$, and 8 , respectively using the proposed hybrid technique. It is clearly observed that scenario 7 the injection of active and reactive power after system reconfiguration increases the reactive power losses. Voltage profile curves for all scenarios are shown in Figure 6. It is clearly indicated that the system voltage profile for scenario 8 is the best. The minimum voltage magnitude of the network is 0.91309 (p.u.), which is improved to $0.93782,0.96867,0.97406,0.97344,0.99206,0.98051$, and 0.99165 using scenarios 2, 3, 4, 5, 6, 7, and 8, respectively. In order to show the performance of the proposed hybrid GWO-PSO, some of the results are compared to different techniques for only for scenarios as the last three scenarios are not illustrated in the compared reference in Table 4. Table 4 shows that the proposed hybrid technique has a greater power loss percentage reduction than FWA for scenario 2, 3, 4, and 5. Comparing the results of percentage reduction in power loss between the proposed hybrid GWO-PSO and FWA, it is observed that the GWO-PSO results are $31.14 \%, 64.74 \%$, $70.95 \%$, and $74.89 \%$, however, the FWA are [30] is $30.93 \%, 56.24 \%, 58.59 \%$, and $66.89 \%$ for scenarios 2 , 3,4 , and 5 . It is observed that the performance of the proposed technique is better than FWA, HSA, GA, and Refined Genetic Algorithm (RGA) in terms of power loss minimization. The authors [30] use sensitivity analysis to identify DG allocation and use one of the optimization methods to find size of the DG. Figure 7 shows the conversion characteristics of GWO, PSO, and hybrid GWO-PSO for scenario 8. PSO reaches a reasonable solution but not the optimal. GWO and hybrid technique reach the optimal solution. It can be observed that the proposed hybrid technique provides the best improvement for both the optimal solution and convergence speed. 
Table 2. Comparison of simulation results for P-Type DG units of a 33-bus system.

\begin{tabular}{|c|c|c|c|c|}
\hline \multicolumn{2}{|c|}{ Scenarios } & \multirow{2}{*}{$\begin{array}{c}\text { GWO } \\
33,34,35,36,37 \\
202.67\end{array}$} & \multirow{2}{*}{$\begin{array}{c}\text { PSO } \\
33,34,35,36,37 \\
202.67\end{array}$} & \multirow{2}{*}{$\begin{array}{c}\text { Proposed Hybrid } \\
\text { GWO-PSO }\end{array}$} \\
\hline Scenario 1 & $\begin{array}{c}\text { Switches opened } \\
\text { P loss }(\mathrm{kW})\end{array}$ & & & \\
\hline Scenario 2 & $\begin{array}{l}\text { Switches opened } \\
\text { P loss }(\mathrm{kW}) \\
\text { reduction } \% \\
\text { Iterations } \\
\text { time (sec) }\end{array}$ & $\begin{array}{c}7,9,14,32,37 \\
139.55 \\
31.14 \% \\
50 \\
52.93 \\
\end{array}$ & $\begin{array}{c}7,9,14,32,37 \\
139.55 \\
31.14 \% \\
50 \\
49.96 \\
\end{array}$ & $\begin{array}{c}7,9,14,32,37 \\
139.55 \\
31.14 \% \\
10 \\
30.61 \\
\end{array}$ \\
\hline Scenario 3 & $\begin{array}{c}\text { Switches opened } \\
\text { DG size in MW } \\
\text { (bus) } \\
\text { P loss (kW) } \\
\text { reduction\% } \\
\text { Iterations }\end{array}$ & $\begin{array}{c}33,34,35,36,37 \\
1.0709(30), 1.0997 \\
(24), 0.7541(14) \\
71.4571 \\
64.74 \% \\
200\end{array}$ & $\begin{array}{c}33,34,35,36,37 \\
1.0714(30), 1.0994 \\
(24), 0.7539(14) \\
71.4571 \\
64.74 \% \\
100\end{array}$ & $\begin{array}{c}33,34,35,36,37 \\
1.0717(30), 1.1003 \\
(24), 0.7540(14) \\
71.4571 \\
64.74 \% \\
60\end{array}$ \\
\hline Scenario 4 & $\begin{array}{l}\text { Switches opened } \\
\text { DG size in Mw } \\
\text { (bus) } \\
\text { P loss (kW) } \\
\text { reduction } \% \\
\text { Iterations }\end{array}$ & $\begin{array}{c}7,9,14,32,37 \\
0.9317(8), 1.0670(24), \\
0.9520(30) \\
58.8769 \\
70.95 \% \\
100\end{array}$ & $\begin{array}{c}7,9,14,32,37 \\
0.9316(8), 1.0681(24), \\
0.9503(30) \\
58.8768 \\
70.95 \% \\
100\end{array}$ & $\begin{array}{c}7,9,14,32,37 \\
0.9316(8), 1.0678(24), \\
0.9507(30) \\
58.8768 \\
70.95 \% \\
100\end{array}$ \\
\hline Scenario 5 & $\begin{array}{l}\text { Switches opened } \\
\text { DG size in MW } \\
\text { (bus) } \\
\text { P loss }(\mathrm{kW}) \\
\text { reduction } \% \\
\text { Iterations }\end{array}$ & $\begin{array}{c}11,28,30,33,34 \\
0.9581(7), 1.1257(25), \\
0.8546(33) \\
50.8905 \\
74.89 \% \\
6000\end{array}$ & $\begin{array}{c}11,28,31,33,34 \\
0.8141(8), 0.7540(17), \\
1.3085(25) \\
51.3088 \\
74.68 \% \\
6000\end{array}$ & $\begin{array}{c}11,28,30,33,34 \\
0.9569(7), 0.7529(17), \\
1.2795(25) \\
50.7175 \\
74.97 \% \\
2000\end{array}$ \\
\hline
\end{tabular}

Table 3. Comparison of simulation results for PQ+-type DG units of a 33-bus system.

\begin{tabular}{|c|c|c|c|c|}
\hline \multicolumn{2}{|c|}{ Scenarios } & GWO & PSO & $\begin{array}{l}\text { Proposed Hybrid } \\
\text { GWO-PSO }\end{array}$ \\
\hline \multirow{7}{*}{ Scenario 6} & Switches opened & $33,34,35,36,37$ & $33,34,35,36,37$ & $33,34,35,36,37$ \\
\hline & \multirow{3}{*}{$\begin{array}{c}\text { DG size in MVA } \\
\text { (bus) }\end{array}$} & $0.7401+\mathrm{j} 0.3533(14)$ & $0.74748+\mathrm{j} 0.3501(14)$ & $0.7474+\mathrm{j} 0.3501(14)$ \\
\hline & & $1.0703+\mathrm{j} 0.4869(24)$ & 1.0782 + j $0.5212(24)$ & $1.0782+\mathrm{j} 0.5212(24)$ \\
\hline & & $1.0389+\mathrm{j} 1.0118(30)$ & $1.0485+\mathrm{j} 1.0209(30)$ & $1.0485+\mathrm{j} 1.0209(30)$ \\
\hline & P loss (KW) & 11.6570 & 11.6299 & 11.6299 \\
\hline & reduction $\%$ & $94.24 \%$ & $94.26 \%$ & $94.26 \%$ \\
\hline & Iterations & 200 & 100 & 100 \\
\hline \multirow{7}{*}{ Scenario 7} & Switches opened & $7,9,14,32,37$ & $7,9,14,32,37$ & $7,9,14,32,37$ \\
\hline & \multirow{3}{*}{$\begin{array}{l}\text { DG size in MVA } \\
\text { (bus) }\end{array}$} & $0.5314+\mathrm{j} 0.3147$ (12) & $1.2444+\mathrm{j} 0.6028(21)$ & $0.9316+j 0.4345(8)$ \\
\hline & & $0.5030+\mathrm{j} 0.1485(16)$ & $1.0413+\mathrm{j} 0.5036(24)$ & $0.9321+\mathrm{j} 0.9530(30)$ \\
\hline & & $1.0403+\mathrm{j} 0.9996(30)$ & 0.9281 + j $0.9510(30)$ & $1.0547+\mathrm{j} 0.5108(24)$ \\
\hline & P loss (KW) & 25.1486 & 18.3104 & 16.3000 \\
\hline & reduction $\%$ & $87.59 \%$ & $90.96 \%$ & $91.95 \%$ \\
\hline & Iterations & 600 & 600 & 200 \\
\hline \multirow{8}{*}{ Scenario 8} & Switches opened & $5,11,13,15,26$ & $7,16,21,25,34$ & $5,11,13,15,23$ \\
\hline & \multirow{3}{*}{$\begin{array}{c}\text { DG size in MVA } \\
\text { (bus) }\end{array}$} & $1.0818+\mathrm{j} 0.5138$ (8) & $0.7826+\mathrm{j} 0.3752(12)$ & $1.09745+\mathrm{j} 0.5593(8)$ \\
\hline & & $1.1327+\mathrm{j} 0.8311(25)$ & $0.9533+\mathrm{j} 0.4627(24)$ & $1.1523+\mathrm{j} 0.8047(25)$ \\
\hline & & $0.7528+\mathrm{j} 0.5720$ & $1.1959+\mathrm{j} 1.0738(30)$ & $0.7491+\mathrm{j} 0.5620(32)$ \\
\hline & P loss $(\mathrm{KW})$ & 8.9540 & 10.8466 & 8.9162 \\
\hline & reduction $\%$ & $94.42 \%$ & $94.64 \%$ & $95.60 \%$ \\
\hline & Iterations & 8000 & 8000 & 3000 \\
\hline & time (s) & $26,054.34$ & $23,909.09$ & $12,184.33$ \\
\hline
\end{tabular}




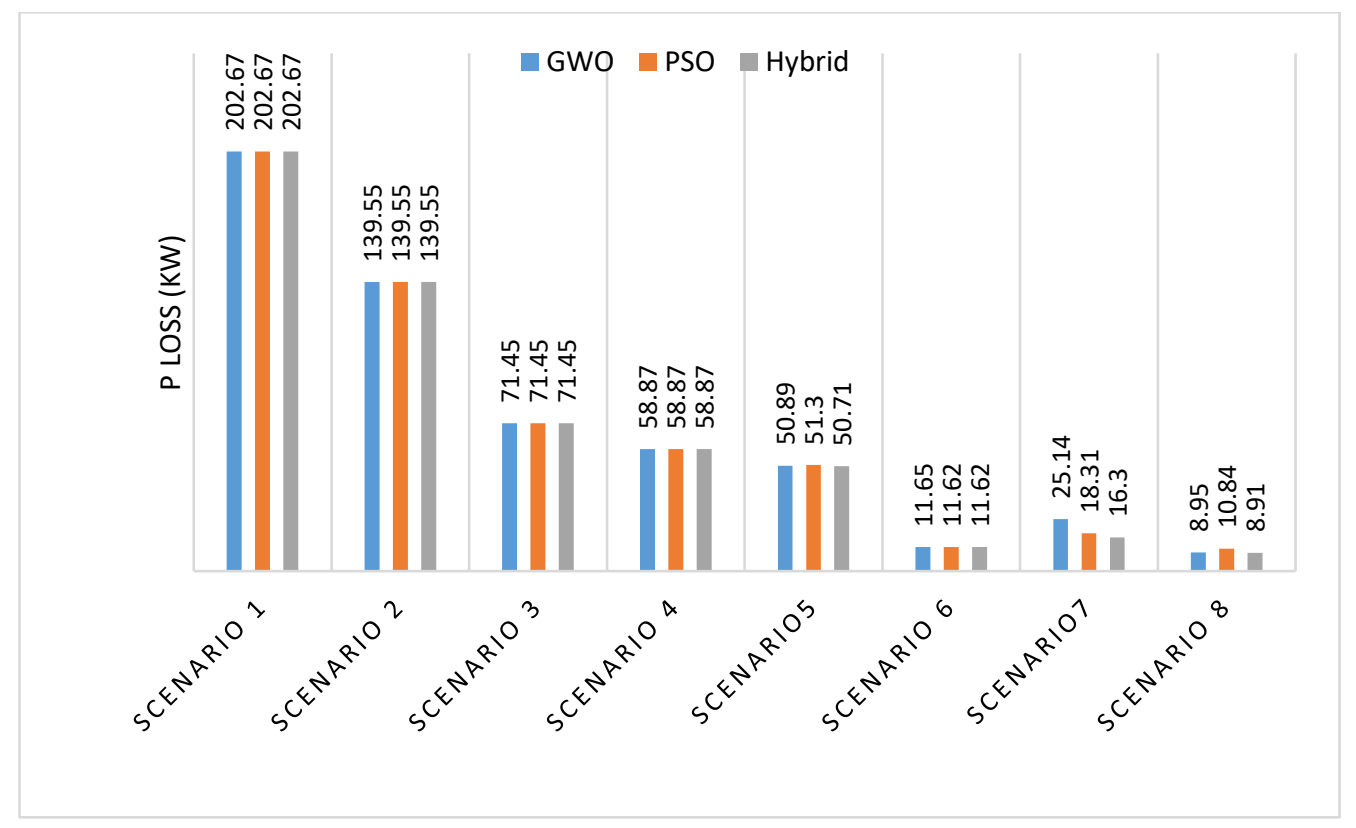

Figure 4. Power loss of a 33-bus system using three different techniques.

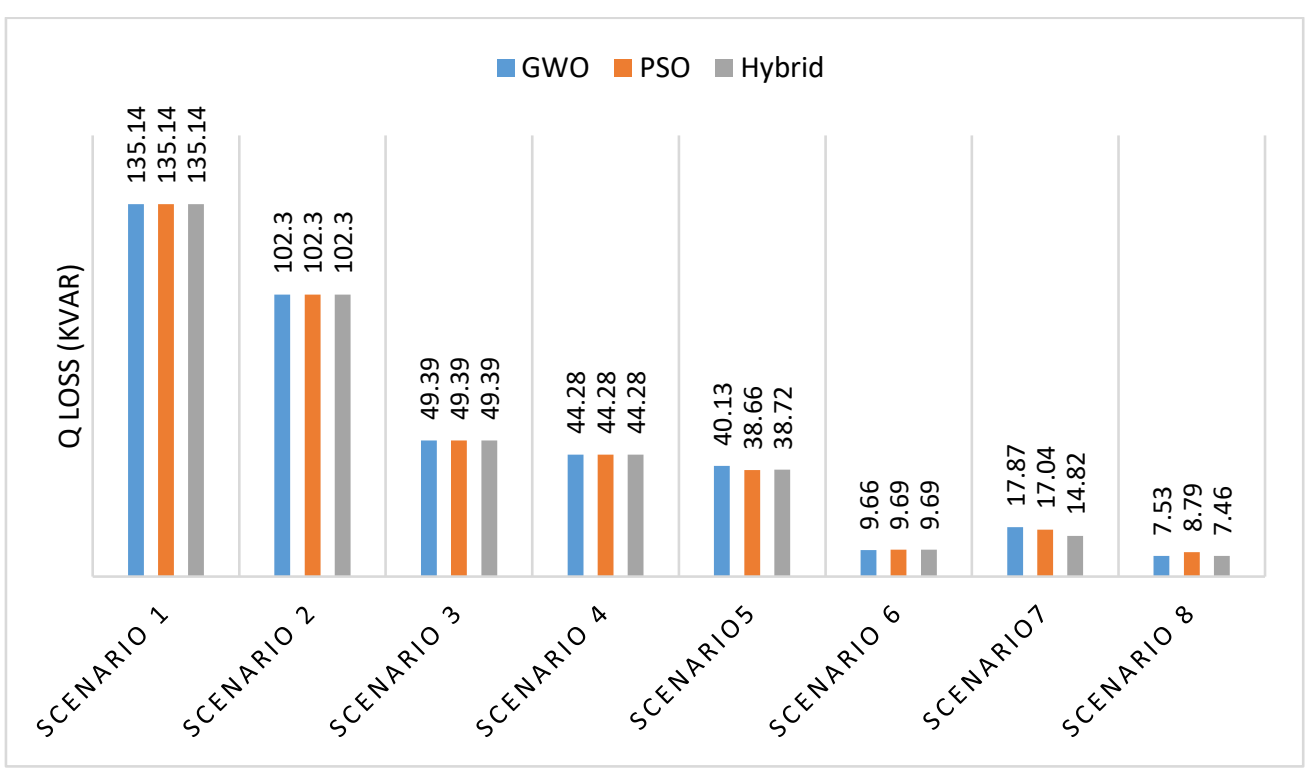

Figure 5. Reactive loss of a 33-bus system using three different techniques. 


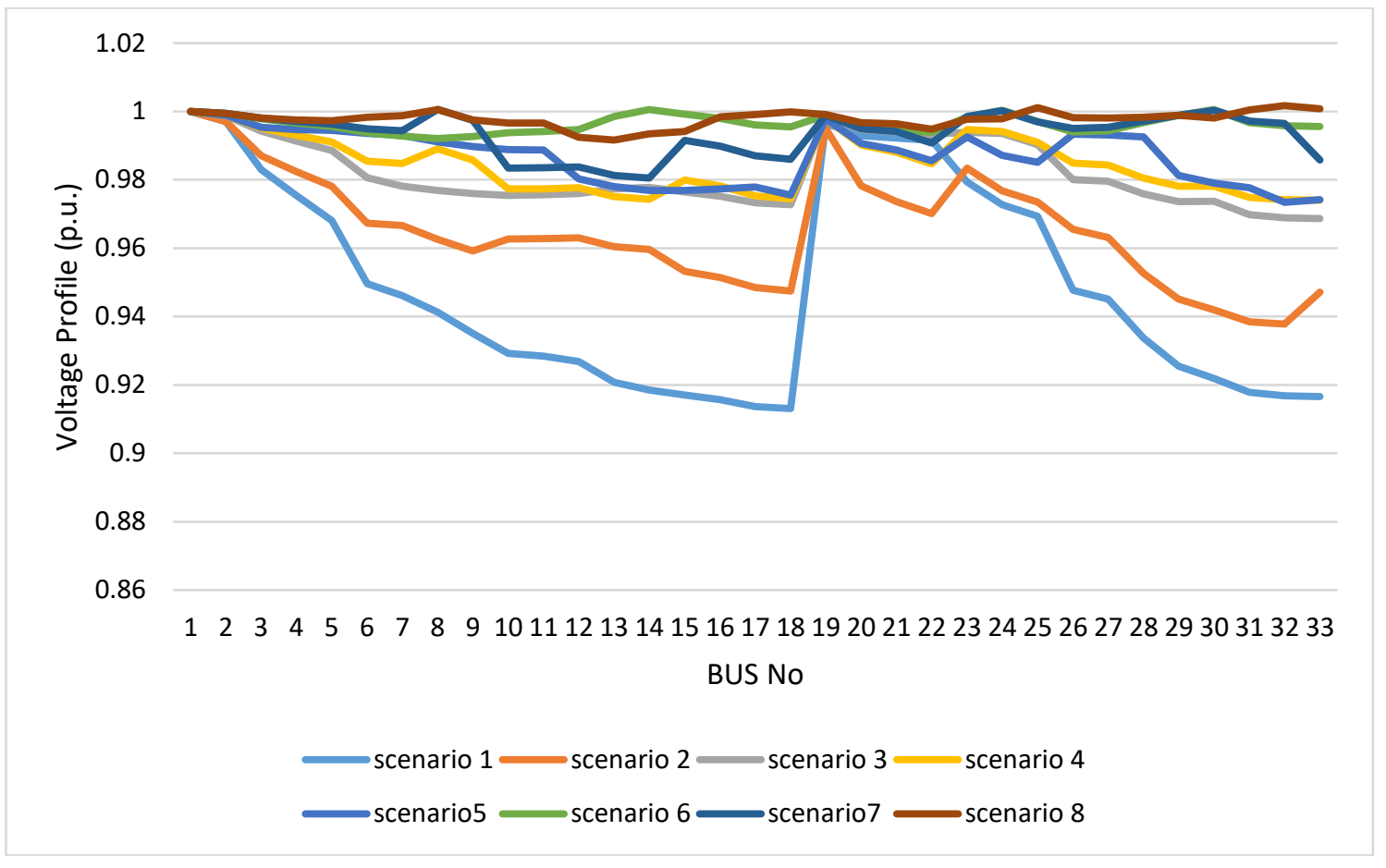

Figure 6. Voltage profile of a 33-bus system using a hybrid technique.

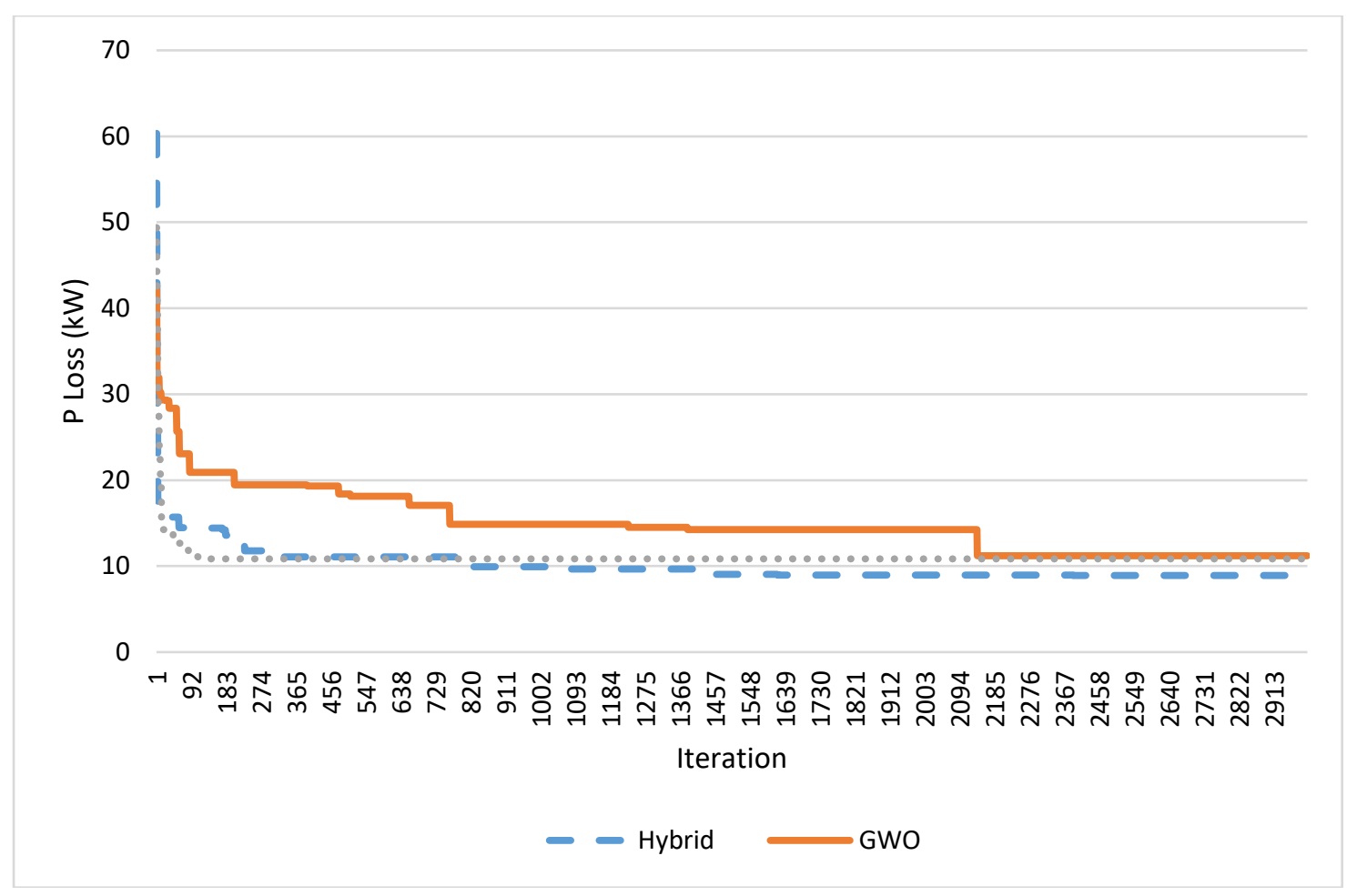

Figure 7. Conversion curve of a 33-bus system using three different techniques for scenario 8. 
Table 4. Comparison of methods performance for the 33-bus system.

\begin{tabular}{|c|c|c|c|c|c|c|}
\hline \multicolumn{2}{|c|}{ Scenarios } & $\begin{array}{c}\text { Proposed Hybrid } \\
\text { GWO-PSO }\end{array}$ & FWA [30] & HSA [30] & GA [30] & RGA [30] \\
\hline \multirow{3}{*}{ Scenario 2} & Switches opened & $7,9,14,32,37$ & $7,9,14,32,28$ & $7,9,14,32,37$ & $33,34,9,36,28$ & $7,9,14,32,37$ \\
\hline & $\mathrm{P}$ loss $(\mathrm{kW})$ & 139.55 & 139.98 & 138.06 & 141.60 & 139.46 \\
\hline & $\mathrm{V}_{\text {worst }}$ (p.u.) & 0.93782 & 0.9413 & 0.9342 & 0.9310 & 0.9315 \\
\hline \multirow{2}{*}{ Scenario 3} & Switches opened & $33,34,35,36,37$ & $33,34,35,36,37$ & $33,34,35,36,37$ & $33,34,35,36,37$ & $33,34,35,36,37$ \\
\hline & $\mathrm{V}_{\text {worst }}$ (p.u.) & 0.96867 & 0.9680 & 0.9670 & 0.9605 & 0.9687 \\
\hline \multirow{4}{*}{ Scenario 4} & Switches opened & $7,9,14,32,37$ & $7,9,14,32,28$ & $7,9,14,32,37$ & $33,34,9,36,28$ & $7,9,14,32,37$ \\
\hline & P loss $(\mathrm{kW})$ & 58.8769 & 83.91 & 97.13 & 98.36 & 98.23 \\
\hline & Reduction \% & $70.95 \%$ & $58.59 \%$ & $52.07 \%$ & $51.46 \%$ & $51.53 \%$ \\
\hline & $\mathrm{V}_{\text {worst }}$ (p.u.) & 0.97406 & 0.9612 & 0.9479 & 0.9506 & 0.9479 \\
\hline
\end{tabular}

\subsection{IEEE 69-Bus Test System}

The system base configuration is having 1-68 sectionalize switches normally closed and 69-73 tie switches are normally opened. The total real and reactive power loads are 3.8 MW and 2.69 MVAR, respectively. The system base capacity is $100 \mathrm{MVA}$ and base voltage is $12.66 \mathrm{KV}$. The limits of real and reactive power injected by DGs are same as test system A. Figure 8 shows the single line diagram for scenario 8. In order to compare the performance of hybrid GWO-PSO, all scenarios are simulated with GWO and PSO results are provided in Tables 5 and 6 . The population size using all the techniques is 50 , $50,50,100,60,60$, and 100 in scenarios 2 to 8 , respectively. The proposed hybrid technique shows the least iteration numbers for all of the scenarios, similar to the IEEE 33-bus system. From Tables 5 and 6 , base case power loss is $224.9295 \mathrm{~kW}$, which is reduced to 3.7132 using scenarios 8 with percentage reduction $98.34 \%$ by integration of DG with $P Q+$ and system reconfiguration simultaneously. From Figure 9, Scenario 7 shows that power loss for PQ+ type DG installation after reconfiguration is not less than the DG installation before reconfiguration and the best improvement in power loss reduction is for scenario 8. From Figure 10, base case reactive loss is $102.1456 \mathrm{kVar}$, which is reduced to 92.0237, $34.9527,34.1729,34.2659,7.2140,6.8968$, and 5.6053 using scenarios 2 to 8 , respectively. Voltage profile curves for all scenarios are shown in Figure 11. It is indicated that system voltage profile for scenario 8 is the best same as the 33-bus test system. The minimum voltage magnitude of the network is 0.90919 (p.u.), which is improved to $0.94947,0.97898,0.98134,0.98133,0.99426,0.99369$, and 0.99486 for scenarios 2 to 8 , respectively, using the proposed hybrid technique. Some of the results are compared to results from previous analysis using different techniques for only four scenarios as in Table 7. Table 7 shows that the percentage power loss reduction for proposed hybrid technique at 69 -bus is lower than the FWA technique. Figure 12 shows the conversion characteristics of GWO, PSO, and hybrid GWO-PSO for scenario 8. It can be observed from Figure 12 that the GWO and PSO reach a reasonable solution but not the optimal. Moreover, PSO is faster than GWO. Also, the proposed hybrid technique provides the best improvement for both optimal solution and convergence speed.

Table 5. Comparison of simulation results for P-type DG units of the 69-bus system.

\begin{tabular}{ccccc}
\hline & Scenarios & GWO & PSO & $\begin{array}{c}\text { Proposed Hybrid } \\
\text { GWO-PSO }\end{array}$ \\
\hline \multirow{2}{*}{ Scenario 1 } & Switches opened & $69,70,71,72,73$ & $69,70,71,72,73$ & $69,70,71,72,73$ \\
& P loss (KW) & 224.9295 & 224.9295 & 224.9295 \\
\hline \multirow{2}{*}{ Scenario 2 } & Switches opened & $14,57,61,69,70$ & $14,57,61,69,70$ & $14,57,61,69,70$ \\
& P loss (KW) & 98.5687 & 98.5687 & 98.5687 \\
& reduction $\%$ & $56.17 \%$ & $56.17 \%$ & $56.17 \%$ \\
& Iterations & 300 & 200 & 30 \\
\hline
\end{tabular}


Table 5. Cont.

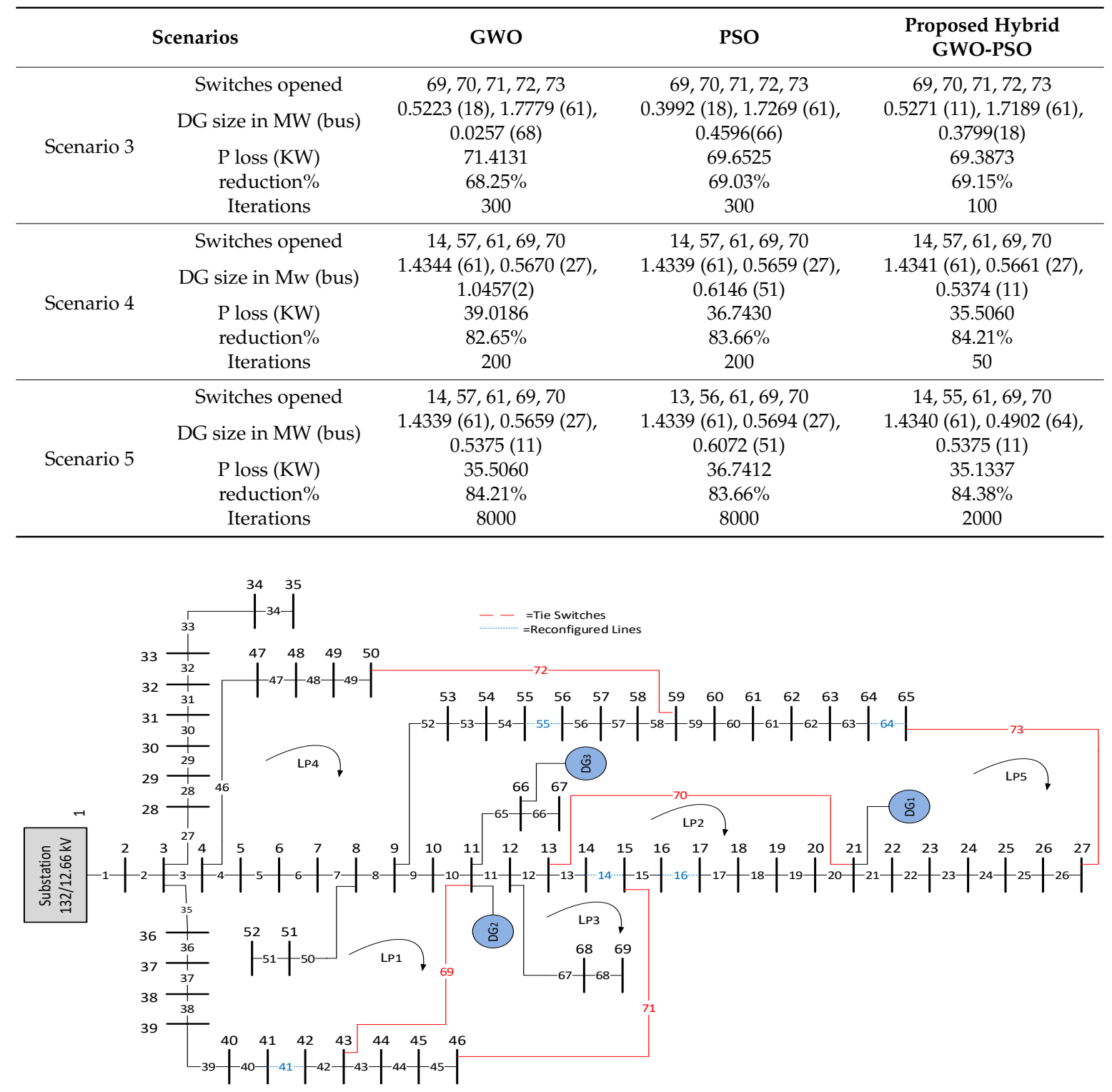

Figure 8. Single line diagram of the 69-bus system for scenario 8.

Table 6. Comparison of simulation results for $\mathrm{PQ}^{+}$-type DG units of the 69-bus system.

\begin{tabular}{|c|c|c|c|c|}
\hline & Scenarios & GWO & PSO & $\begin{array}{c}\text { Proposed Hybrid } \\
\text { GWO-PSO }\end{array}$ \\
\hline \multirow{5}{*}{ Scenario 6} & Switches opened & $69,70,71,72,73$ & $69,70,71,72,73$ & $69,70,71,72,73$ \\
\hline & DG size in MVA (bus) & $1.6913+j 1.2438(61)$ & $1.7345+\mathrm{j} 1.2383(61)$ & $1.6917+\mathrm{j} 1.2081(61)$ \\
\hline & & $0.7718+\mathrm{j} 0.2386(68)$ & $0.5219+\mathrm{j} 0.3530(17)$ & $0.3180+\mathrm{j} 0.2111(21)$ \\
\hline & P loss $(\mathrm{KW})$ & 9.5920 & 7.1709 & 4.4863 \\
\hline & Iterations & 300 & 300 & 100 \\
\hline \multirow[b]{4}{*}{ Scenario 7} & Switches opened & $14,57,61,69,70$ & $14,57,61,69,70$ & $14,57,61,69,70$ \\
\hline & & $0.0871+\mathrm{j} 0.2096(68)$ & $0.6137+\mathrm{j} 0.4385(51)$ & $0.5366+\mathrm{j} 0.3826(11)$ \\
\hline & DG size in MVA (bus) & $1.4155+\mathrm{j} 1.0131(61)$ & $1.4171+\mathrm{j} 1.01236(6)$ & $1.4167+\mathrm{j} 1.0129(61)$ \\
\hline & & $0.5643+\mathrm{j} 0.3856(27)$ & $0.5629+\mathrm{j} 0.3904(27)$ & $0.5629+\mathrm{j} 0.3900(27)$ \\
\hline
\end{tabular}


Table 6. Cont.

\begin{tabular}{ccccc}
\hline & Scenarios & GWO & PSO & $\begin{array}{c}\text { Proposed Hybrid } \\
\text { GWO-PSO }\end{array}$ \\
\hline & Switches opened & $8,13,20,24,55$ & $12,21,40,53,70$ & $14,16,41,55,64$ \\
& & $0.08778+\mathrm{j} 0.5722(2)$ & $1.7298+\mathrm{j} 1.2346(61)$ & $0.4319+\mathrm{j} 0.2913(21)$ \\
Scenario 8 & DG size in MVA (bus) & $0.8475+\mathrm{j} 0.5899(11)$ & $0.7649+\mathrm{j} 0.5493(50)$ & $0.5897+\mathrm{j} 0.4161(11)$ \\
& & $1.7651+\mathrm{j} 1.2605(61)$ & $0.7791+\mathrm{j} 0.5339(43)$ & $1.6770+\mathrm{j} 1.1979(61)$ \\
& P loss (KW) & 5.4798 & 4.40472 & 3.7132 \\
& reduction\% & $97.56 \%$ & $98.04 \%$ & $98.34 \%$ \\
& Iterations & 10000 & 10000 & 3000 \\
\hline
\end{tabular}

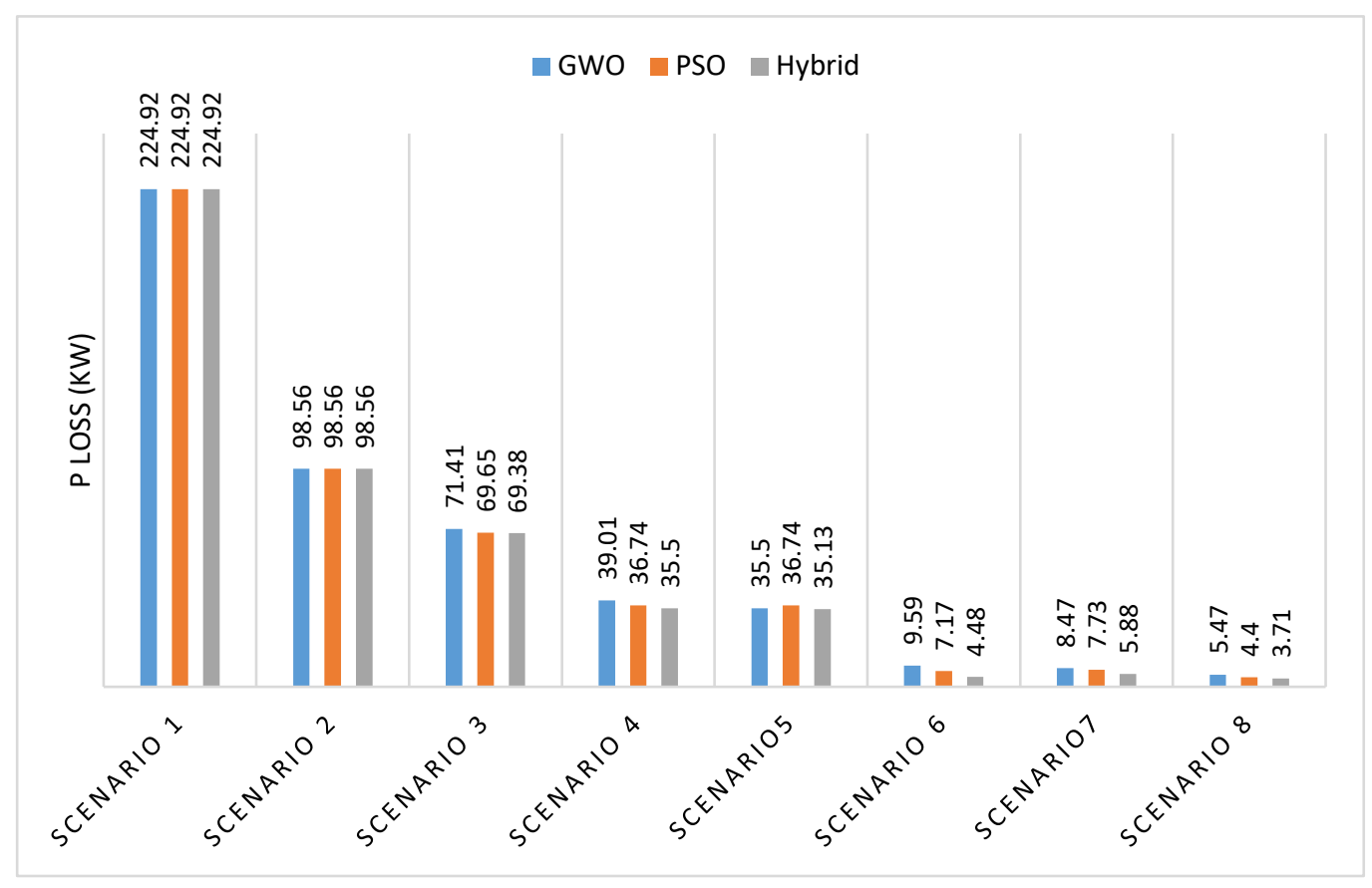

Figure 9. Power loss of the 69-bus system using three different techniques.

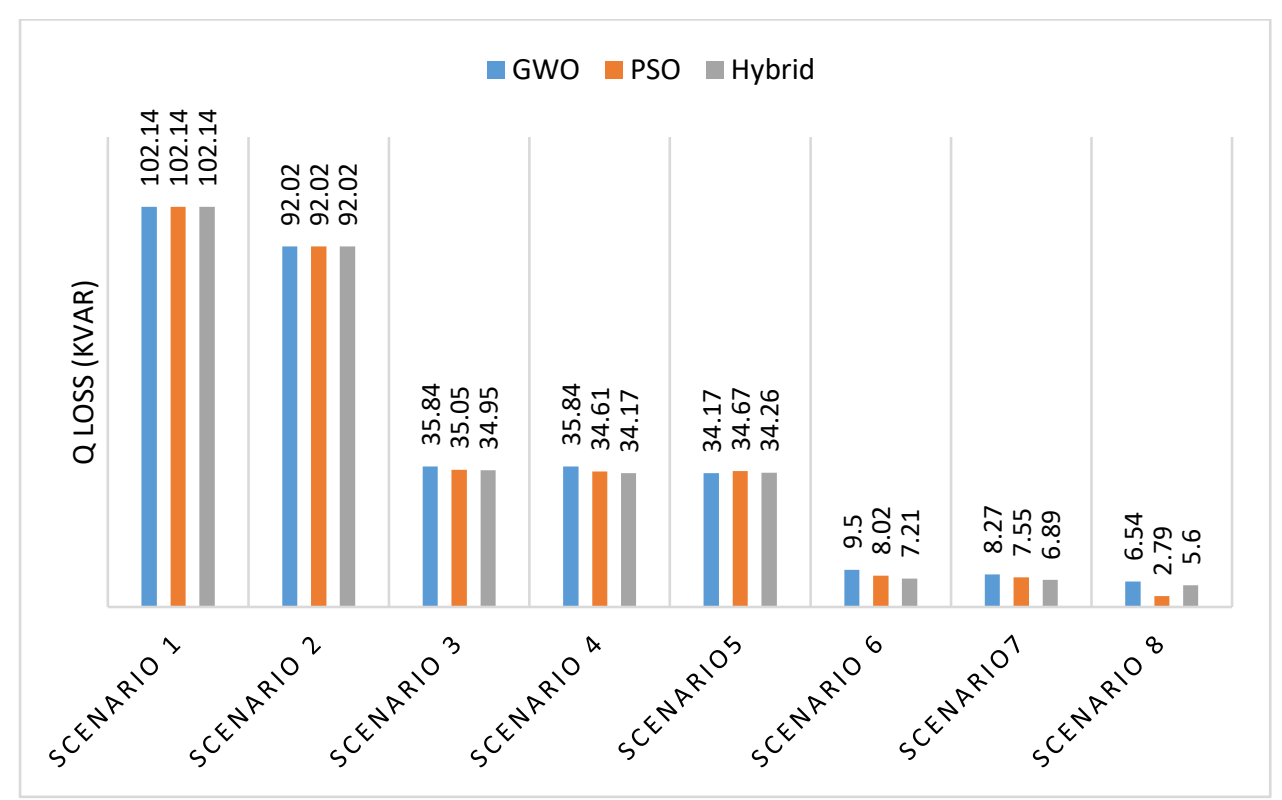

Figure 10. Reactive loss of the 69-bus system using three different techniques. 


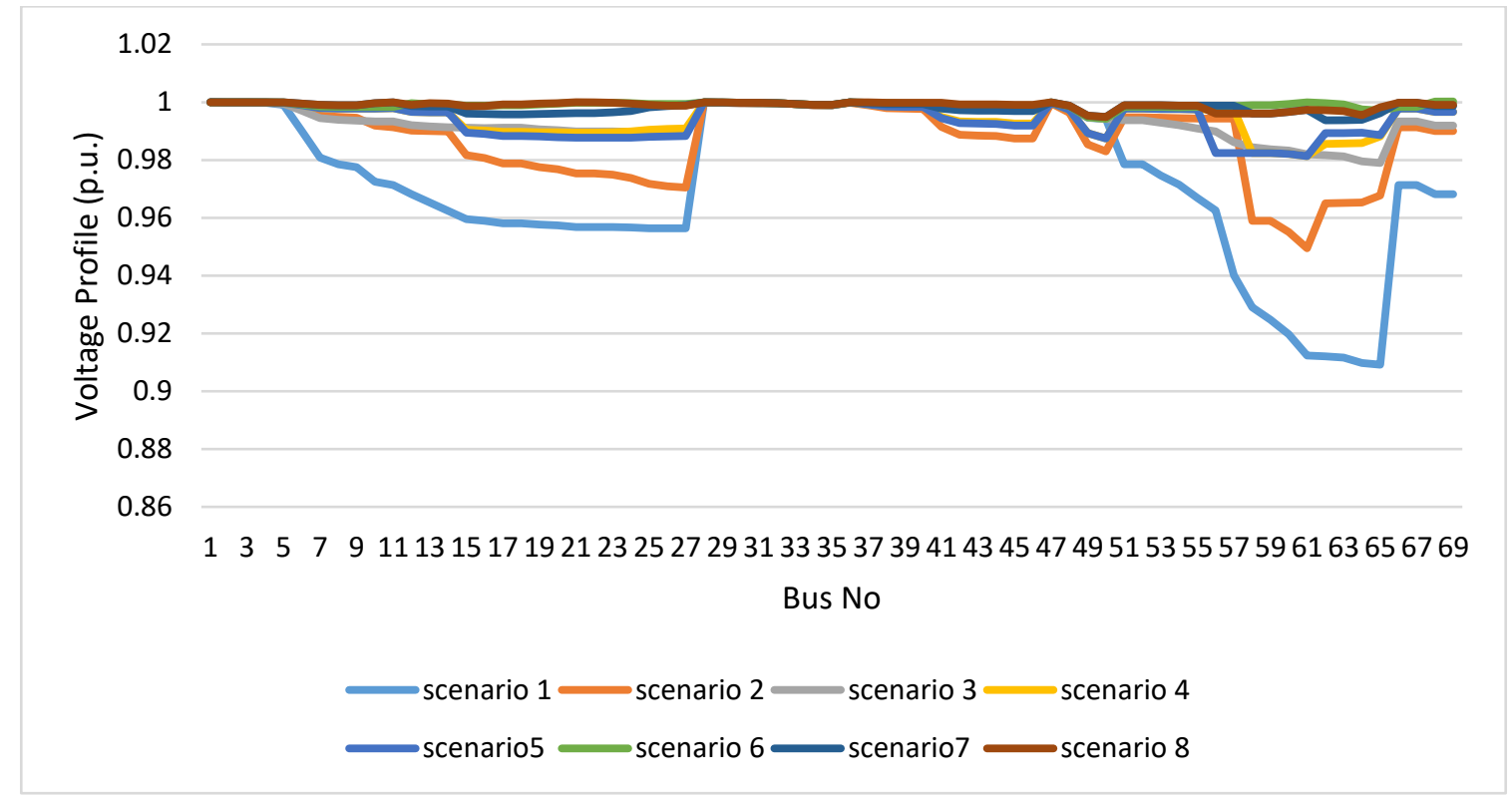

Figure 11. Voltage profile of the 69-bus system using the hybrid technique.

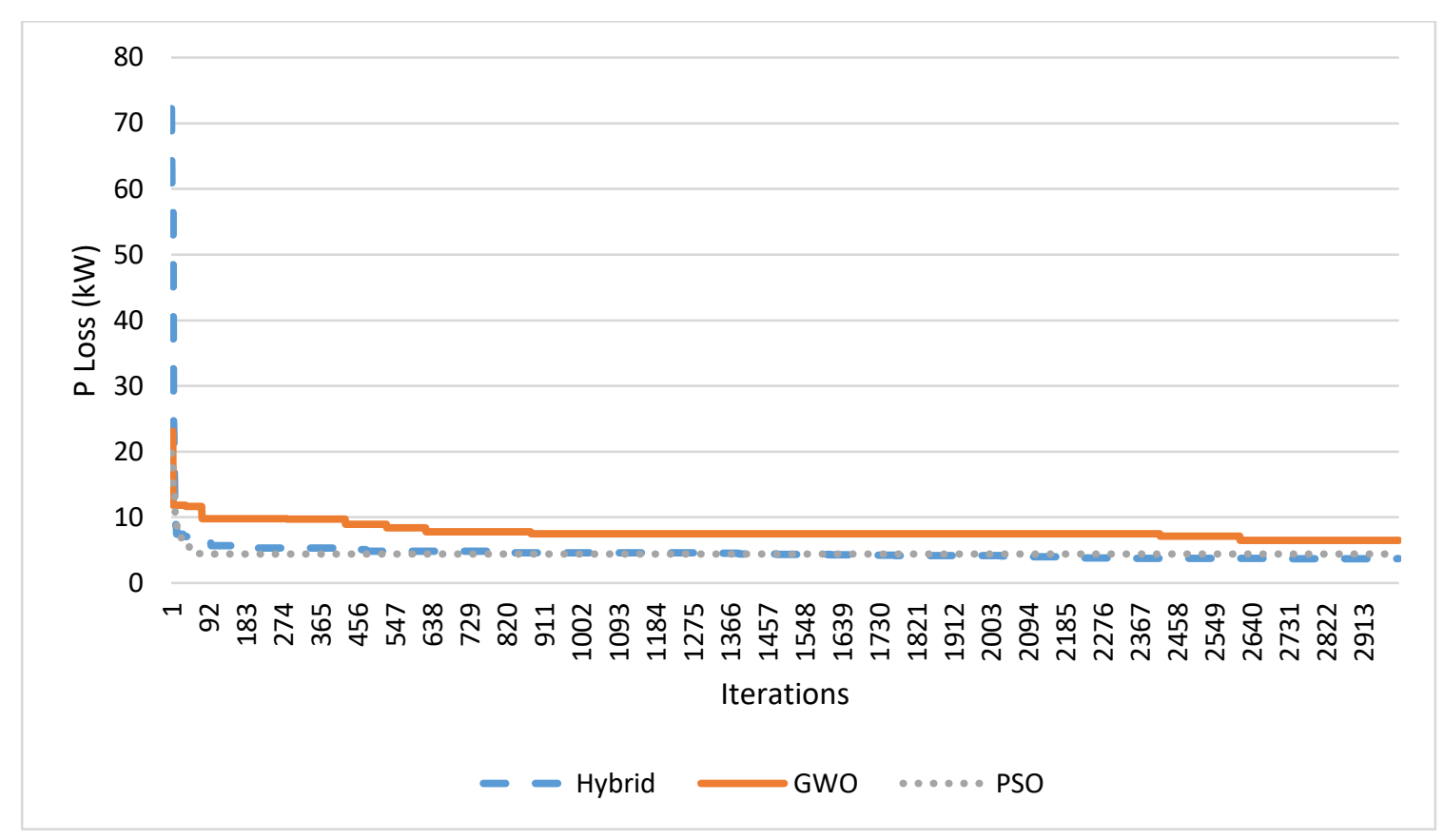

Figure 12. Conversion curve of the 69-bus system using three different methods for scenario 8.

Table 7. Comparison of methods performance for the 69-bus system.

\begin{tabular}{ccccccc}
\hline \multicolumn{2}{c}{ Scenarios } & $\begin{array}{c}\text { Proposed Hybrid } \\
\text { GWO-PSO }\end{array}$ & FWA [30] & HSA [30] & GA [30] & RGA [30] \\
& Switches opened & $14,57,61,69,70$ & $14,56,61,69,70$ & $69,18,13,56,61$ & $69,70,14,53,61$ & $69,17,13,55,61$ \\
Scenario 2 & P loss (kW) & 98.5687 & 98.59 & 99.35 & 103.29 & 100.28 \\
& Reduction $\%$ & $56.17 \%$ & $56.17 \%$ & $55.85 \%$ & $54.08 \%$ & $55.42 \%$ \\
& $V_{\text {worst }}$ (p.u.) & 0.94947 & 0.9495 & 0.9428 & 0.9411 & 0.9428 \\
\hline \multirow{2}{*}{ Scenario 3 } & Switches opened & $69,70,71,72,73$ & $69,70,71,72,73$ & $69,70,71,72,73$ & $69,70,71,72,73$ & $69,70,71,72,73$ \\
& P loss (kW) & 69.3873 & 77.85 & 86.77 & 88.5 & 67.65 \\
& Reduction $\%$ & $69.15 \%$ & $65.39 \%$ & $61.43 \%$ & $60.66 \%$ & 0.9687 \\
\hline
\end{tabular}


Table 7. Cont.

\begin{tabular}{|c|c|c|c|c|c|c|}
\hline \multicolumn{2}{|c|}{ Scenarios } & $\begin{array}{l}\text { Proposed Hybrid } \\
\text { GWO-PSO }\end{array}$ & FWA [30] & HSA [30] & GA [30] & RGA [30] \\
\hline \multirow{4}{*}{ Scenario 4} & Switches opened & $14,57,61,69,70$ & $14,56,61,69,70$ & $69,18,13,56,61$ & $69,70,14,53,61$ & $69,17,13,55,61$ \\
\hline & P loss $(\mathrm{kW})$ & 35.5060 & 43.88 & 51.30 & 54.53 & 52.34 \\
\hline & Reduction $\%$ & $84.21 \%$ & $80.49 \%$ & $77.20 \%$ & $75.76 \%$ & $76.73 \%$ \\
\hline & $\mathrm{V}_{\text {worst }}$ (p.u.) & 0.98134 & 0.9720 & 0.9619 & 0.9401 & 0.9611 \\
\hline \multirow{4}{*}{ Scenario 5} & Switches opened & $14,55,61,69,70$ & $69,70,13,55,63$ & $69,17,13,58,61$ & $10,15,45,55,62$ & $10,16,14,55,62$ \\
\hline & P loss $(\mathrm{kW})$ & 35.1337 & 39.25 & 40.30 & 46.20 & 44.23 \\
\hline & Reduction \% & $84.38 \%$ & $82.55 \%$ & $82.08 \%$ & $73.38 \%$ & $80.32 \%$ \\
\hline & $\mathrm{V}_{\text {worst }}$ (p.u.) & 0.98133 & 0.9796 & 0.9736 & 0.9727 & 0.9742 \\
\hline
\end{tabular}

\subsection{The 78-Bus Real Test System}

This system test data is a real recorded data from the distribution system of Cairo and it is given in Table A1. The system base configuration consists of having 1-78 sectionalized switches normally closed, whereas five switches are normally opened. The total real and reactive power loads are $48.25 \mathrm{MW}$ and 20.99 MVAR, respectively. The system base capacity is $1.5 \mathrm{MVA}$ and base voltage is $22 \mathrm{KV}$. The limits of real and reactive power injected by DGs are 0 to $20 \mathrm{MW}$ and 0 to 10 MVAR, respectively. Tables 8 and 9 illustrate the comparison in the same way as test systems A and B. As shown in Tables 8 and 9, base case power loss is $421.7192 \mathrm{~kW}$, which is reduced to 48.6045 using scenario 8, i.e., a percentage power loss reduction of $88.47 \%$. The base case reactive loss is $572.3431 \mathrm{KVar}$ which is reduced to $65.9645 \mathrm{Kvar}$. System losses are very small compared to the load capacity due to the fact that the loads are industrial and are located directly after the substation. Figure 13 shows that power loss reduction for scenario 8 is higher than any other scenario as it performs the system reconfiguration, sizing, and siting of DGs in parallel. Figure 14 shows the reactive power loss from different scenarios using the three optimization techniques. Comparing the results from the hybrid technique it can been clearly seen that the reactive power loss is reduced to $284.1545,192.6667,146.0921,120.7269,121.1049,120.1029$, and 65.9645 for scenarios 2 to 8 , respectively, using the proposed hybrid technique. Voltage profile curves for all scenarios are shown in Figure 15. Similar to test systems A and B, the voltage profile for scenario 8 is the best. The minimum voltage magnitude of the network is 0.97046 (p.u.), which is improved to $0.99139,0.98552,0.99161,0.99231,0.99161,0.99161$, and 0.99598 using scenarios $2,3,4,5,6,7$, and 8 , respectively. The population size using all techniques is $50,60,60,100,60,60$, and 100 in scenarios 2 to 8 , respectively. Tables show that the proposed hybrid technique takes the least number of iterations for the most of the scenarios, similar to the two IEEE test systems. Figure 16 shows the conversion characteristics of GWO, PSO, and hybrid GWO-PSO for scenario 8 where GWO and PSO did not reach the optimal solution. PSO is faster than GWO. However, GWO is with a better solution than PSO. Furthermore, the proposed technique shows the best results compared to the results obtained from the IEEE test systems.

Table 8. Comparison of simulation results for P-type DG units of the 78-bus system.

\begin{tabular}{ccccc}
\hline & Scenarios & GWO & PSO & $\begin{array}{c}\text { Proposed Hybrid } \\
\text { GWO-PSO }\end{array}$ \\
\hline \multirow{2}{*}{ Scenario 1 } & Switches opened & $32,34,40,48,63$ & $32,34,40,48,63$ & $32,34,40,48,63$ \\
& P loss (KW) & 421.7192 & 421.7192 & 421.7192 \\
\hline \multirow{2}{*}{ Scenario 2 } & Switches opened & $10,28,34,45,64$ & $10,28,34,45,64$ & $10,28,34,45,64$ \\
& P loss (KW) & 209.3731 & 209.3731 & 209.3731 \\
& reduction $\%$ & $50.3525 \%$ & $50.3525 \%$ & $50.3525 \%$ \\
& Iterations & 100 & 100 & 30 \\
\hline \multirow{5}{*}{ Scenario 3 } & Switches opened & $32,34,40,48,63$ & $32,34,40,48,63$ & $32,34,40,48,63$ \\
& DG size in MW (bus) & $6.6347(67), 9.4411$ & $6.6392(67), 8.3307$ & $9.0871(7), 13.0333$ \\
& P loss (KW) & $(5), 13.0352(29)$ & $(32), 11.4460(52)$ & $(29), 6.6383(67)$ \\
& reduction $\%$ & 142.0250 & 154.9977 & 141.9624 \\
& Iterations & $66.32 \%$ & $63.24 \%$ & $66.33 \%$ \\
\hline
\end{tabular}


Table 8. Cont.

\begin{tabular}{ccccc}
\hline & Scenarios & GWO & PSO & $\begin{array}{c}\text { Proposed Hybrid } \\
\text { GWO-PSO }\end{array}$ \\
\hline & Switches opened & $10,28,34,45,64$ & $10,28,34,45,64$ & $10,28,34,45,64$ \\
Scenario 4 & DG size in Mw (bus) & $\begin{array}{c}5.4594(75), 10.5558 \\
(3), 6.5508(67)\end{array}$ & $\begin{array}{c}5.1046(43), 10.3781 \\
(16), 6.55061(67)\end{array}$ & $\begin{array}{c}5.5491(25), 10.3774 \\
(16), 6.5501(67)\end{array}$ \\
& P loss (KW) & 107.6866 & 109.2588 & 107.6448 \\
& reduction $\%$ & $74.4648 \%$ & $74.092 \%$ & $74.47 \%$ \\
Scenario 5 5 & 300 & 300 & 100 \\
& Iterations & $8,23,30,43,64$ & $8,26,34,41,64$ & $8,23,30,43,64$ \\
& Switches opened & $15.8913(32), 5.4580$ & $9.1835(32), 5.8525$ & $6.5505(67), 5.4581$ \\
& DG size in MW (bus) & $(75), 6.5507(67)$ & $(31), 6.9573(25)$ & $(75), 15.8910(32)$ \\
& P loss (KW) & 88.9550 & 115.6147 & 88.9550 \\
& reduction $\%$ & $78.90 \%$ & $72.5849 \%$ & $78.90 \%$ \\
\end{tabular}

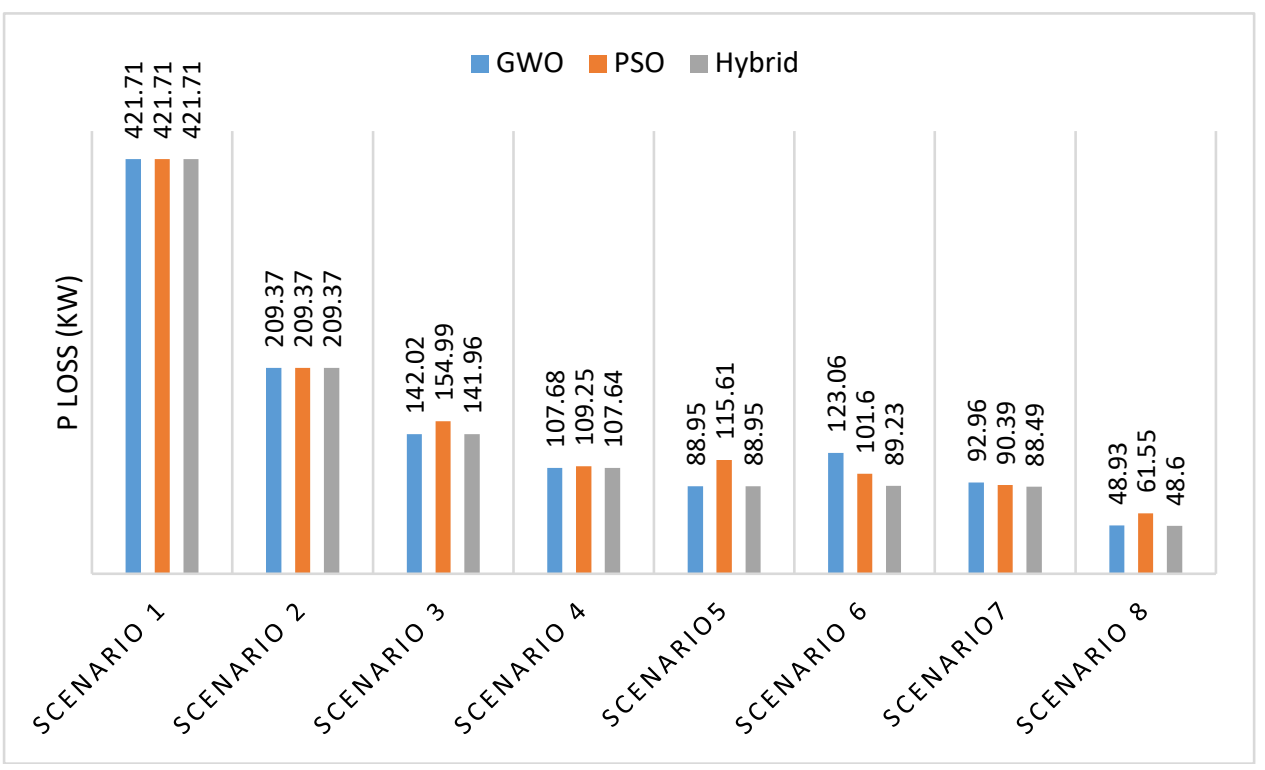

Figure 13. Power loss of the 78-bus system using three different techniques.

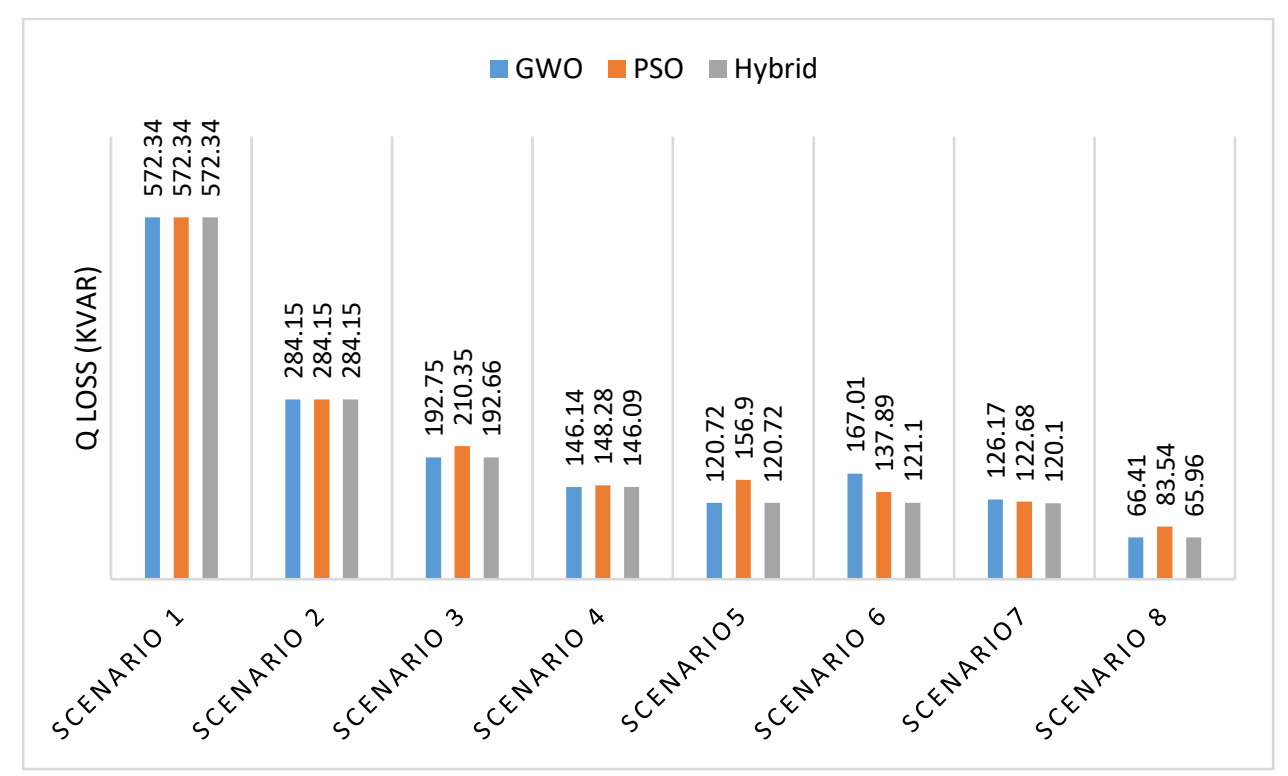

Figure 14. Reactive loss of the 78-bus system using three different techniques. 


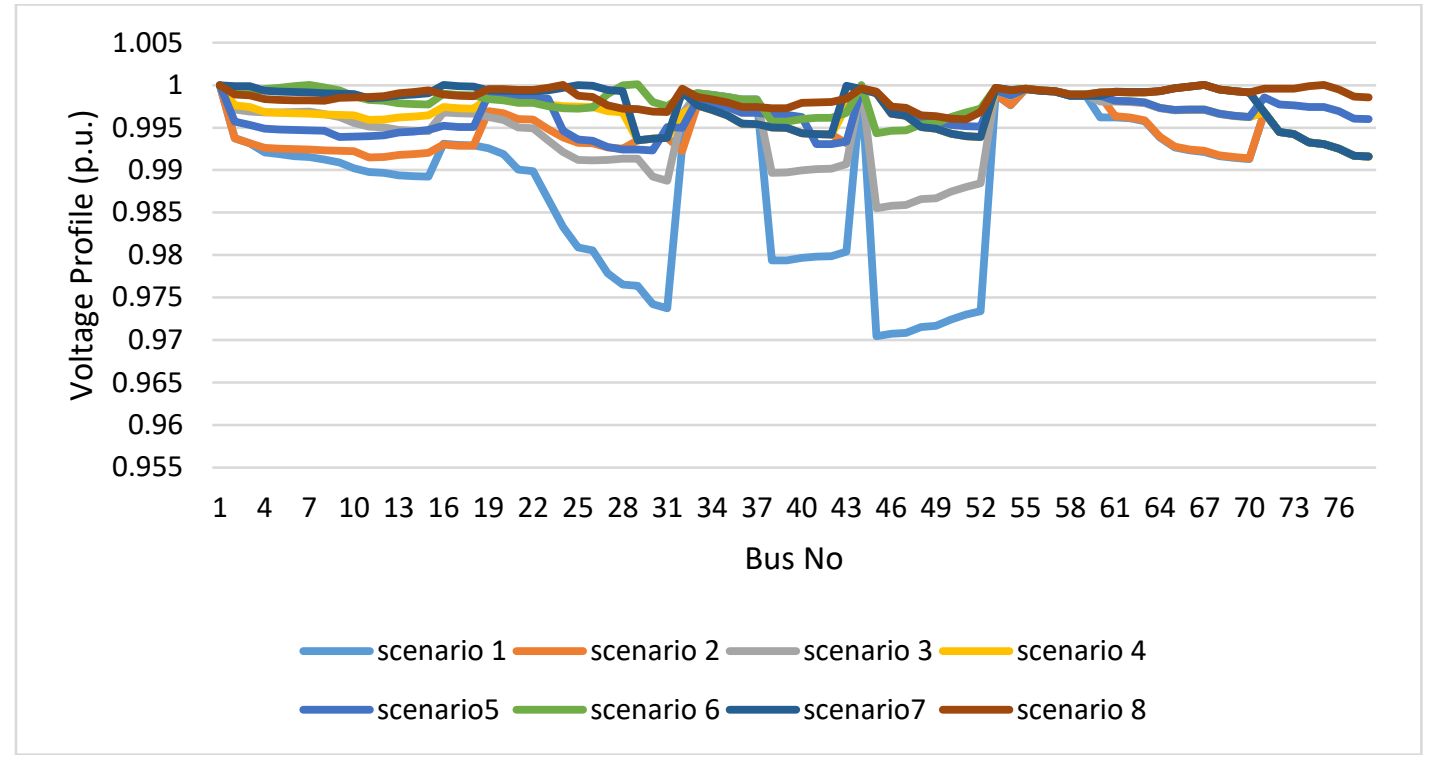

Figure 15. Voltage profile of the 78-bus system using the hybrid technique.

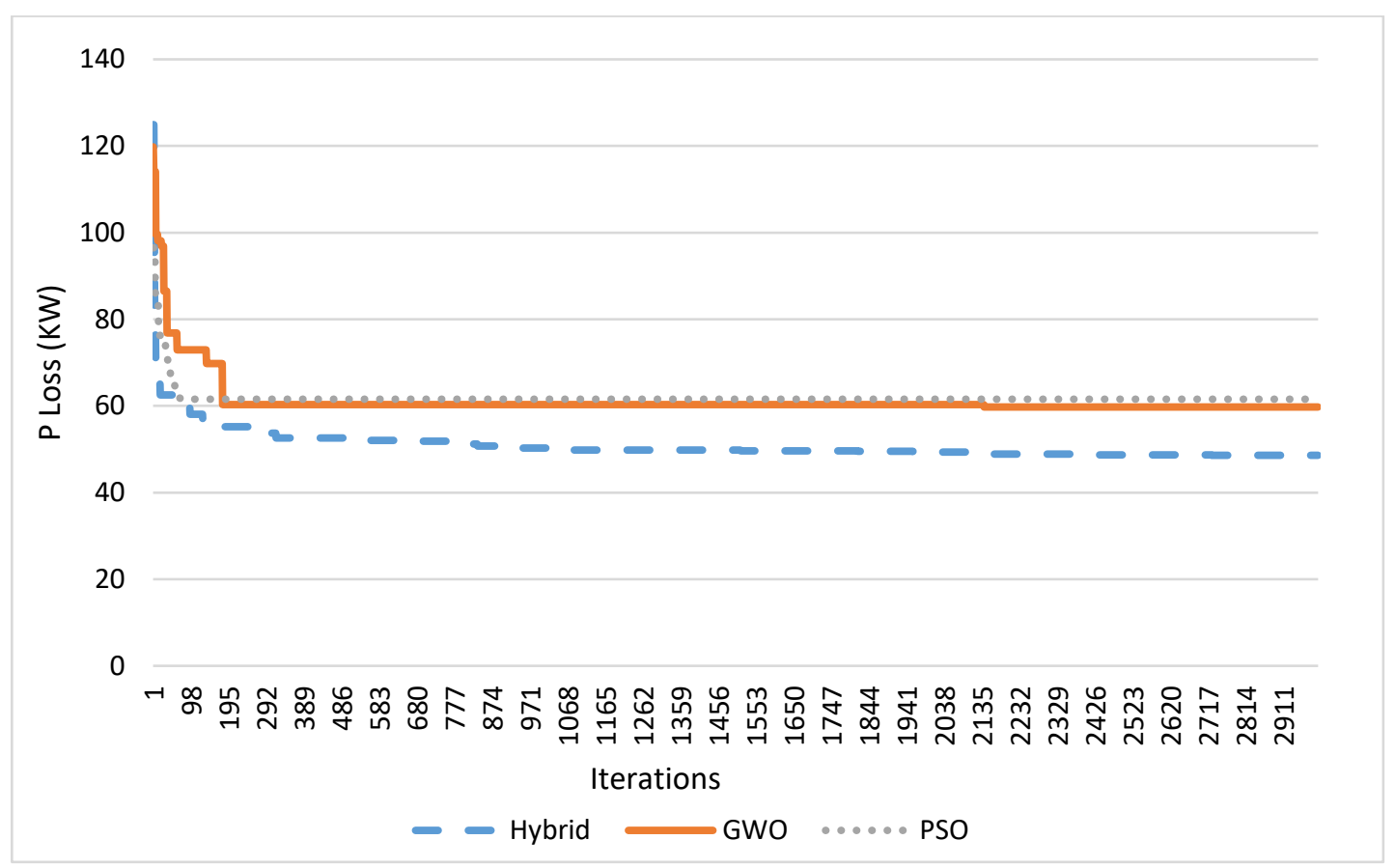

Figure 16. Conversion curve of the 78-bus system using three different methods for scenario 8.

Table 9. Comparison of simulation results for $\mathrm{PQ}^{+}$-type DG units of the 78-bus system.

\begin{tabular}{ccccc}
\hline \multicolumn{1}{c}{ Scenarios } & GWO & PSO & $\begin{array}{c}\text { Proposed Hybrid } \\
\text { GWO-PSO }\end{array}$ \\
\hline & Switches opened & $32,34,40,48,63$ & $32,34,40,48,63$ & $32,34,40,48,63$ \\
& DG size in MVA & $4.2811+\mathrm{j} 0.0002(11)$ & $7.0371+\mathrm{j} 3.0773(31)$ & $13.0438+\mathrm{j} 5.7339(29)$ \\
Scenario 6 & (bus) & $6.2412+\mathrm{j} 4.5606(3)$ & $9.0865+\mathrm{j} 3.9673(7)$ & $6.6376+\mathrm{j} 2.8963(67)$ \\
& P loss (KW) & $12.9952+\mathrm{j} 5.6954(29)$ & $8.3189+\mathrm{j} 3.6267(25)$ & $9.0840+\mathrm{j} 3.9653(7)$ \\
& reduction\% & 723.0646 & 101.6025 & 89.2335 \\
& Iterations & $70.81 \%$ & $75.91 \%$ & $78.84 \%$ \\
\hline
\end{tabular}


Table 9. Cont.

\begin{tabular}{ccccc}
\hline \multicolumn{1}{c}{ Scenarios } & GWO & PSO & $\begin{array}{c}\text { Proposed Hybrid } \\
\text { GWO-PSO }\end{array}$ \\
\hline & Switches opened & $10,28,34,45,64$ & $10,28,34,45,64$ & $10,28,34,45,64$ \\
& DG size in MVA & $6.5494+\mathrm{j} 2.7644(67)$ & $10.3709+\mathrm{j} 4.5219(16)$ & $6.5530+\mathrm{j} 2.8517(67)$ \\
Scenario 7 & (bus) & $5.4412+\mathrm{j} 0.0273(75)$ & $5.1071+\mathrm{j} 2.2269(43)$ & $10.3680+\mathrm{j} 4.5201(16)$ \\
& P loss (KW) & $10.5141+\mathrm{j} 4.5881(3)$ & $6.5514+\mathrm{j} 2.8547(67)$ & $5.5462+\mathrm{j} 2.4208(25)$ \\
& reduction\% & 92.9695 & 90.3978 & 88.4952 \\
& Iterations & $77.95 \%$ & $78.56 \%$ & $79.01 \%$ \\
& Switches opened & 800 & 300 & 100 \\
\hline \multirow{5}{*}{ Scenario 8 8} & $8,21,42,55,63$ & $8,20,41,51,63$ & $8,20,42,55,63$ \\
& DG size in MVA & $5.4565+\mathrm{j} 2.3783(75)$ & $6.6404+\mathrm{j} 2.8937(67)$ & $18.4208+\mathrm{j} 8.0511(24)$ \\
& (bus) & $18.2086+\mathrm{j} 7.9589(32)$ & $16.2463+\mathrm{j} 7.0932(24)$ & $6.6400+\mathrm{j} 2.8937(67)$ \\
& P loss (KW) & $6.6405+\mathrm{j} 2.8940(67)$ & $5.7228+\mathrm{j} 2.4958(31)$ & $5.4565+\mathrm{j} 2.3779(75)$ \\
& reduction\% & 48.93 & 61.5560 & 48.6045 \\
& Iterations & $88.39 \%$ & $85.40 \%$ & $88.47 \%$ \\
\hline
\end{tabular}

This work presents system reconfiguration and DGs allocation and sizing for 33-bus and 69-bus IEEE systems and a 78-real distribution system located in Cairo, Egypt. The presented study proposes a new hybrid GWO-PSO technique. The validity of the technique is held by comparing the performance of the proposed new hybrid GWO-PSO technique to GWO and PSO individually for the same objective function of minimization of power losses. This combination of the two metaheuristic techniques leads to the elimination of the disadvantages of both techniques, the minimization of the number of iterations and helps reach the optimal solution at every simulation. This paper also compares the proposed technique to the results obtained from previous work in terms of power loss minimization.

In the IEEE 33-bus system, active power loss decreases from 202.67 to $8.1962 \mathrm{~kW}$, reactive power loss decreases from 135.141 to $7.4668 \mathrm{kVar}$ and the minimum voltage magnitude improved from 0.91309 to 0.99165 (p.u.) relative to the scheme without considering system reconfiguration and DG placement.

In the IEEE 69-bus system, active power loss decreases from 224.9295 to $3.7132 \mathrm{~kW}$, reactive power loss decreases from 102.1456 to $5.6053 \mathrm{kVar}$, and the minimum voltage magnitude improved from 0.90919 to 0.99486 (p.u.).

In the 78-bus real system, active power loss decreases from 421.7192 to $48.6045 \mathrm{~kW}$, reactive power loss decreases from 572.3431 to $65.9645 \mathrm{kVar}$ and the minimum voltage magnitude increased from 0.97046 to 0.99598 (p.u.).

From the later results, it is observed that using power loss as an objective function improves all the other elements of the network. Moreover, the combination of network reconfiguration and optimal placement of DG units has the best improvement compared to solving each one of them separately. The results show that the performance of the proposed hybrid GWO-PSO technique is better than the other techniques in terms of number of iteration, conversion speed, and power loss minimization.

\section{Conclusions}

This paper presents a new hybrid GWO-PSO technique used to optimally allocate and size DGs in order to reduce power losses. It considers large search spaces system reconfiguration and DG allocation and sizing for 33-bus and 69-bus IEEE systems and a 78-bus real distribution system located at Cairo, Egypt. The validity of the technique is held by comparing the performance of the proposed new hybrid GWO-PSO technique to GWO and PSO individually. This combination of the two metaheuristic techniques leads to the elimination of the disadvantages of each technique when applied individually, reduces the number of iterations, and ensures that the optimal solution is reached during every simulation.

To check the validity of the proposed technique, results were compared to a reference that uses sensitivity analysis to identify DG allocation and optimization methods to find size of the DG. 
This comparison showed that the performance of the proposed technique outperformed FWA, HSA, GA, and Refined Genetic Algorithm (RGA) in terms of power loss minimization.

Hybrid PSO-GWO; although PSO is a very fast optimization technique, it may sometimes do not reach the optimal solution in large search spaces. Consequently, this does not allow GWO to reach the optimal solution. Thus, it is observed that initializing the hybridization by GWO leads to better results than by PSO as GWO is more accurate than PSO in large searching spaces.

Furthermore, the case studies also showed that the proposed technique is faster and requires a smaller number of iterations that applying PSO or GWO individually. On one hand, although PSO reaches a reasonable solution faster than the GWO technique, it is not reliable as it may not reach the optimum in all cases. On the other hand, the GWO technique reaches a more accurate solution than PSO in all cases despite the system size. Therefore, due to the nature of the nonlinear behavior of the problem and the size of the systems used, running GWO or PSO optimization particularly will not lead to the same results at each run and may not reach the optimal solution. Thus, the results may be averaged to increase the accuracy.

Author Contributions: All authors were responsible for conceptualizing the framework, writing and editing, and reviewing the paper.

Funding: This research received no external funding.

Conflicts of Interest: The authors declare there are no conflict of interest.

\section{Appendix A}

Table A1. Test data for a 78-bus system.

\begin{tabular}{|c|c|c|c|c|c|c|}
\hline Switch No. & From bus $i$ & To bus $i+1$ & $\mathrm{Ri}, i+1$ & $\mathrm{X} \mathbf{i}, i+1$ & $\mathrm{P}(\mathrm{KW})$ & $\mathrm{Q}(\mathrm{kVar})$ \\
\hline 1 & 1 & 2 & 0.178125 & 0.241746 & 685.8921 & 298.3631 \\
\hline 2 & 2 & 3 & 0.016875 & 0.022902 & 685.8921 & 298.3631 \\
\hline 3 & 3 & 4 & 0.0525 & 0.071251 & 717.069 & 311.925 \\
\hline 4 & 4 & 5 & 0.0125 & 0.016965 & 748.2459 & 325.487 \\
\hline 5 & 5 & 6 & 0.0125 & 0.016965 & 174.5907 & 75.94696 \\
\hline 6 & 6 & 7 & 0.00875 & 0.011875 & 286.8276 & 124.77 \\
\hline 7 & 7 & 8 & 0.02 & 0.027143 & 748.2459 & 325.487 \\
\hline 8 & 8 & 9 & 0.03 & 0.040715 & 244.427 & 106.3257 \\
\hline 9 & 9 & 10 & 0.06125 & 0.083127 & 255.6507 & 111.2081 \\
\hline 10 & 10 & 11 & 0.04375 & 0.059376 & 1153.546 & 501.7924 \\
\hline 11 & 11 & 12 & 0.015625 & 0.021206 & 236.9446 & 103.0709 \\
\hline 12 & 12 & 13 & 0.055625 & 0.075492 & 265.0038 & 115.2766 \\
\hline 13 & 13 & 14 & 0.0175 & 0.02375 & 717.069 & 311.925 \\
\hline 14 & 14 & 15 & 0.02 & 0.027143 & 685.8921 & 298.3631 \\
\hline 15 & 3 & 16 & 0.008125 & 0.011027 & 717.069 & 311.925 \\
\hline 16 & 16 & 17 & 0.0375 & 0.050894 & 685.8921 & 298.3631 \\
\hline 17 & 17 & 18 & 0.025 & 0.033929 & 436.4768 & 189.8674 \\
\hline 18 & 1 & 19 & 0.13125 & 0.178128 & 286.8276 & 124.77 \\
\hline 19 & 19 & 20 & 0.0125 & 0.016965 & 729.5398 & 317.3498 \\
\hline 20 & 20 & 21 & 0.03375 & 0.045804 & 717.069 & 311.925 \\
\hline 21 & 21 & 22 & 0.00375 & 0.005089 & 271.2392 & 117.989 \\
\hline 22 & 22 & 23 & 0.06625 & 0.089912 & 654.7152 & 284.8011 \\
\hline 23 & 23 & 24 & 0.06875 & 0.093305 & 685.8921 & 298.3631 \\
\hline 24 & 24 & 25 & 0.0525 & 0.071251 & 717.069 & 311.925 \\
\hline 25 & 25 & 26 & 0.0125 & 0.016965 & 748.2459 & 325.487 \\
\hline 26 & 26 & 27 & 0.0975 & 0.132324 & 729.5398 & 317.3498 \\
\hline 27 & 27 & 28 & 0.05375 & 0.072948 & 735.7752 & 320.0622 \\
\hline 28 & 28 & 29 & 0.00625 & 0.008482 & 654.7152 & 284.8011 \\
\hline 29 & 29 & 30 & 0.10625 & 0.144199 & 249.4153 & 108.4957 \\
\hline 30 & 30 & 31 & 0.025 & 0.033929 & 467.6537 & 203.4294 \\
\hline 31 & 31 & 52 & 0.01875 & 0.025447 & 1153.546 & 501.7924 \\
\hline 32 & 32 & 15 & 0.02 & 0.027143 & 149.6492 & 65.0974 \\
\hline 33 & 32 & 16 & 0.055 & 0.074644 & 202.6499 & 88.15273 \\
\hline 34 & 24 & 32 & 0.015 & 0.020358 & 277.4745 & 120.7014 \\
\hline 35 & 1 & 33 & 0.1375 & 0.186611 & 685.8921 & 298.3631 \\
\hline 36 & 33 & 34 & 0.03125 & 0.042412 & 779.4229 & 339.0489 \\
\hline
\end{tabular}


Table A1. Cont.

\begin{tabular}{|c|c|c|c|c|c|c|}
\hline Switch No. & From bus $i$ & To bus $i+1$ & $\mathrm{Ri}, i+1$ & $\mathrm{X} \mathbf{i}, i+1$ & $\mathbf{P}(\mathrm{KW})$ & Q(kVar) \\
\hline 37 & 34 & 35 & 0.04 & 0.054287 & 286.8276 & 124.77 \\
\hline 38 & 35 & 36 & 0.06375 & 0.086519 & 685.8921 & 298.3631 \\
\hline 39 & 36 & 37 & 0.0025 & 0.003393 & 748.2459 & 325.487 \\
\hline 40 & 37 & 38 & 0.0375 & 0.050894 & 717.069 & 311.925 \\
\hline 41 & 38 & 39 & 0.00875 & 0.011875 & 717.069 & 311.925 \\
\hline 42 & 39 & 40 & 0.0875 & 0.118752 & 723.3044 & 314.6374 \\
\hline 43 & 40 & 41 & 0.02125 & 0.02884 & 654.7152 & 284.8011 \\
\hline 44 & 41 & 42 & 0.005 & 0.006786 & 748.2459 & 325.487 \\
\hline 45 & 42 & 43 & 0.05375 & 0.072948 & 717.069 & 311.925 \\
\hline 46 & 43 & 25 & 0.0375 & 0.050894 & 748.2459 & 325.487 \\
\hline 47 & 1 & 44 & 0.019625 & 0.026634 & 748.2459 & 325.487 \\
\hline 48 & 44 & 45 & 0.0225 & 0.030536 & 685.8921 & 298.3631 \\
\hline 49 & 45 & 46 & 0.1225 & 0.166253 & 748.2459 & 325.487 \\
\hline 50 & 46 & 47 & 0.015 & 0.020358 & 685.8921 & 298.3631 \\
\hline 51 & 47 & 48 & 0.09125 & 0.123842 & 174.5907 & 75.94696 \\
\hline 52 & 48 & 49 & 0.01375 & 0.018661 & 717.069 & 311.925 \\
\hline 53 & 49 & 50 & 0.0625 & 0.084823 & 717.069 & 311.925 \\
\hline 54 & 50 & 51 & 0.0375 & 0.050894 & 174.5907 & 75.94696 \\
\hline 55 & 51 & 52 & 0.025 & 0.033929 & 717.069 & 311.925 \\
\hline 56 & 1 & 53 & 0.03625 & 0.049197 & 221.3561 & 96.2899 \\
\hline 57 & 53 & 54 & 0.04375 & 0.059376 & 729.5398 & 317.3498 \\
\hline 58 & 1 & 55 & 0.05 & 0.067858 & 717.069 & 311.925 \\
\hline 59 & 55 & 56 & 0.025 & 0.033929 & 236.9446 & 103.0709 \\
\hline 60 & 56 & 57 & 0.01625 & 0.022054 & 26.81215 & 11.66328 \\
\hline 61 & 57 & 58 & 0.08125 & 0.11027 & 748.2459 & 325.487 \\
\hline 62 & 58 & 59 & 0.00625 & 0.008482 & 685.8921 & 298.3631 \\
\hline 63 & 59 & 60 & 0.01125 & 0.015268 & 1122.369 & 488.2305 \\
\hline 64 & 60 & 61 & 0.04875 & 0.066162 & 1122.369 & 488.2305 \\
\hline 65 & 61 & 62 & 0.005 & 0.006786 & 374.123 & 162.7435 \\
\hline 66 & 62 & 63 & 0.015 & 0.020358 & 685.8921 & 298.3631 \\
\hline 67 & 63 & 64 & 0.09375 & 0.127235 & 1122.369 & 488.2305 \\
\hline 68 & 64 & 65 & 0.06875 & 0.093305 & 685.8921 & 298.3631 \\
\hline 69 & 65 & 66 & 0.025 & 0.033929 & 1091.192 & 474.6685 \\
\hline 70 & 66 & 67 & 0.015625 & 0.021206 & 748.2459 & 325.487 \\
\hline 71 & 67 & 68 & 0.053125 & 0.0721 & 143.4138 & 62.38501 \\
\hline 72 & 68 & 69 & 0.0375 & 0.050894 & 1122.369 & 488.2305 \\
\hline 73 & 69 & 70 & 0.039375 & 0.053438 & 685.8921 & 298.3631 \\
\hline 74 & 61 & 54 & 0.05375 & 0.072948 & 1091.192 & 474.6685 \\
\hline 75 & 1 & 71 & 0.15625 & 0.212058 & 717.069 & 311.925 \\
\hline 76 & 71 & 72 & 0.12625 & 0.171342 & 685.8921 & 298.3631 \\
\hline 77 & 72 & 73 & 0.015 & 0.020358 & 1028.838 & 447.5446 \\
\hline 78 & 73 & 74 & 0.06875 & 0.093305 & & \\
\hline 79 & 74 & 75 & 0.01875 & 0.025447 & & \\
\hline 80 & 75 & 76 & 0.0625 & 0.084823 & & \\
\hline 81 & 76 & 77 & 0.1525 & 0.206968 & & \\
\hline 82 & 77 & 78 & 0.02 & 0.027143 & & \\
\hline
\end{tabular}

\section{References}

1. Haggar, M.F.A.; Beshr, E.; Eteiba, M.B. Minimizing Power Loss in Distribution System by Optimal Sizing and Sitting of Distributed Generators with Network Reconfiguration Using Grey Wolf and Particle Swarm Optimizers. In Proceedings of the 2018 IEEE International Conference on Environment and Electrical Engineering and 2018 IEEE Industrial and Commercial Power Systems Europe (EEEIC/I CPS Europe), Palermo, Italy, 12-15 June 2018; pp. 1-6.

2. Hussien, S.A.; Mahmoud, H. Optimal Placement and Sizing of DGs in Distribution System for Improving Voltage Profile and Reducing the Power Loss using Moth Flame Optimization Technique. Int. J. Sci. Res. Eng. Technol. 2017, 6, 161-167.

3. Sanjay, R.; Jayabarathi, T.; Raghunathan, T.; Ramesh, V.; Mithulananthan, N. Optimal allocation of distributed generation using hybrid grey Wolf optimizer. IEEE Access 2017, 5, 14807-14818. [CrossRef]

4. Sultana, U.; Khairuddin, A.B.; Mokhtar, A.S.; Zareen, N.; Sultana, B. Grey wolf optimizer based placement and sizing of multiple distributed generation in the distribution system. Energy 2016, 111, 525-536. [CrossRef] 
5. Sobieh, A.R.; Mandour, M.; Saied, E.M.; Salama, M.M. Optimal Number Size and Location of Distributed Generation Units in Radial Distribution Systems Using Grey Wolf Optimizer. Int. Electr. Eng. J. 2017, 7, 2367-2376.

6. Ras Guerriche, K.; Bouktir, T. Optimal Allocation and Sizing of Distributed Generation with Particle Swarm Optimization Algorithm for Loss Reduction. Sci. Technol. 2015, 6, 59-69.

7. Bhumkittipich, K.; Phuangpornpitak, W. Optimal Placement and Sizing of Distributed Generation for Power Loss Reduction Using Particle Swarm Optimization. Energy Procedia 2013, 34, 307-317. [CrossRef]

8. Dixit, M.; Kundu, P.; Jariwala, H.R. Optimal placement and sizing of DG in Distribution system using Artificial Bee Colony Algorithm. In Proceedings of the 2016 IEEE 6th International Conference on Power Systems ICPS, New Delhi, India, 4-6 March 2016; pp. 1-6. [CrossRef]

9. Seker, A.A.; Hocaoglu, M.H. Artificial Bee Colony algorithm for optimal placement and sizing of distributed generation. In Proceedings of the 2013 8th International Conference on Electrical and Electronics Engineering (ELECO), Bursa, Turkey, 28-30 November 2013; pp. 127-131. [CrossRef]

10. Remha, S.; Chettih, S.; Arif, S. Optimal placement of different DG units type in distribution networks based on voltage stability maximization and minimization of power losses. In Proceedings of the 2016 8th International Conference on Modelling, Identification and Control (ICMIC), Algiers, Algeria, 15-17 November 2016; pp. 867-873. [CrossRef]

11. Uniyal, A.; Kumar, A. Comparison of optimal DG placement using CSA, GSA, PSO and GA for minimum real power loss in radial distribution system. In Proceedings of the 2016 IEEE 6th International Conference on Power Systems (ICPS), New Delhi, India, 4-6 March 2016; pp. 1-6. [CrossRef]

12. Dharageshwari, K.; Nayanatara, C. Multiobjective optimal placement of multiple distributed generations in IEEE 33 bus radial system using simulated annealing. In Proceedings of the IEEE International Conference on Circuits, Power and Computing Technologies (ICCPCT 2015), Nagercoil, India, 19-20 March 2015. [CrossRef]

13. Singh, N.; Ghosh, S.; Murari, K. Optimal Sizing and Placement of DG in a Radial Distribution Network using Sensitivity based methods. Int. Electr. Eng. J. 2015, 6, 1727-1734.

14. Mahmoud, K.B.; Yorino, N.; Ahmed, A. Optimal Distributed Generation Allocation in Distribution Systems for Loss Minimization. IEEE Trans. Power Syst. 2016, 31, 960-969. [CrossRef]

15. El-Fergany, A. Optimal allocation of multi-type distributed generators using backtracking search optimization algorithm. Int. J. Electr. Power Energy Syst. 2015, 64, 1197-1205. [CrossRef]

16. Moradi, M.H.; Abedini, M. A combination of genetic algorithm and particle swarm optimization for optimal DG location and sizing in distribution systems. Int. J. Electr. Power Energy Syst. 2012, 34, 66-74. [CrossRef]

17. Aman, M.M.; Jasmon, G.B.; Bakar, A.H.A.; Mokhlis, H. Optimum network reconfiguration based on maximization of system loadability using continuation power flow theorem. Int. J. Electr. Power Energy Syst. 2014, 54, 123-133. [CrossRef]

18. Nguyen, T.T.; Truong, A.V. Distribution network reconfiguration for power loss minimization and voltage profile improvement using cuckoo search algorithm. Int. J. Electr. Power Energy Syst. 2015, 68, $233-242$. [CrossRef]

19. Sathish Kumar, K.; Jayabarathi, T. Power system reconfiguration and loss minimization for an distribution systems using bacterial foraging optimization algorithm. Int. J. Electr. Power Energy Syst. 2012, 36, 13-17. [CrossRef]

20. Savier, J.S.; Das, D. Impact of network reconfiguration on loss allocation of radial distribution systems. IEEE Trans. Power Deliv. 2007, 22, 2473-2480. [CrossRef]

21. Venkatesh, B.; Chandramohan, S.; Kayalvizhi, N.; Devi, R.P.K. Optimal reconfiguration of radial distribuion system using artificial intelligence methods. In Proceedings of the 2009 IEEE Toronto International Conference Science and Technology for Humanity (TIC-STH), Toronto, ON, Canada, 26-27 September 2009.

22. Assadian, M.; Farsangi, M.M.; Nezamabadi-Pour, H. Optimal Reconfiguration of Distribution System by PSO and GA using graph theory. In Proceedings of the 6th WSEAS International Conference on Applications of Electrical Engineering, Istanbul, Turkey, 27-29 May 2007; pp. 83-88.

23. Sedighizadeh, M.; Dakhem, M.; Sarvi, M.; Kordkheili, H.H. Optimal reconfiguration and capacitor placement for power loss reduction of distribution system using improved binary particle swarm optimization. Int. J. Energy Environ. Eng. 2014, 5, 1-11. [CrossRef] 
24. Gomes, F.V.; Carneiro, S.; Member, S.; Pereira, J.L.R.; Member, S.; Vinagre, M.P.; Augusto, P.; Garcia, N.; De Araujo, L.R. Approach Using Optimum Power Flow and Sensitivity Analysis for Loss Reduction. IEEE Trans. Power Syst. 2006, 21, 1616-1623. [CrossRef]

25. Liu, K.Y.; Sheng, W.; Liu, Y.; Meng, X. A network reconfiguration method considering data uncertainties in smart distribution networks. Energies 2017, 10, 618. [CrossRef]

26. Xing, H.; Sun, X. Distributed generation locating and sizing in active distribution network considering network reconfiguration. IEEE Access 2017, 5, 14768-14774. [CrossRef]

27. Mokhlis, H.; Jasmon, G.B.; Aman, M.M.; Bakar, A.H.A. Optimum tie switches allocation and DG placement based on maximisation of system loadability using discrete artificial bee colony algorithm. IET Gener. Transm. Distrib. 2016, 10, 2277-2284. [CrossRef]

28. Taher, S.A.; Karimi, M.H. Optimal reconfiguration and DG allocation in balanced and unbalanced distribution systems. Ain Shams Eng. J. 2014, 5, 735-749. [CrossRef]

29. Rao, R.S.; Ravindra, K.; Satish, K.; Narasimham, S.V.L. Power Loss Minimization in Distribution System Using Network Reconfiguration in the Presence of Distributed Generation. IEEE Trans. Power Syst. 2012, 28, 1-9. [CrossRef]

30. Mohamed Imran, A.; Kowsalya, M.; Kothari, D.P. A novel integration technique for optimal network reconfiguration and distributed generation placement in power distribution networks. Int. J. Electr. Power Energy Syst. 2014, 63, 461-472. [CrossRef]

31. Kaur, M.; Ghosh, S. Effective Loss Minimization and Allocation of Unbalanced Distribution Network. Energies 2017, 10, 1931. [CrossRef]

32. Ghosh, A.; Kumar, D.; Samantaray, S.R. Simultaneous reconfiguration with DG placement using bit-shift operator based TLBO. In Proceedings of the 2016 National Power Systems Conference (NPSC), Bhubaneswar, India, 19-21 December 2016. [CrossRef]

33. Ali Hormozi, M. Optimal Network Reconfiguration and Distributed Generation Placement in Distribution System Using a Hybrid Algorithm. Int. J. Energy Power Eng. 2016, 5, 163-170. [CrossRef]

34. Nawaz, S.; Imran, M.; Sharma, A.K.; Jain, A. Optimal feeder reconfiguration and DG placement in distribution network. Int. J. Appl. Eng. Res. 2016, 11, 4878-4885.

35. Vidyasagar, S.; Vijayakumar, K.; Ramanujam, R.; Sattianadan, D.; Kumar, N. Voltage profile improvement using DG in reconfigured distribution system. Int. J. Control Autom. 2015, 8, 393-410. [CrossRef]

36. Rajaram, R.; Sathish Kumar, K.; Rajasekar, N. Power system reconfiguration in a radial distribution network for reducing losses and to improve voltage profile using modified plant growth simulation algorithm with Distributed Generation (DG). Energy Rep. 2015, 1, 116-122. [CrossRef]

37. Nasir, M.N.M.; Shahrin, N.M.; Sulaima, M.F.; Jali, M.H.; Baharom, M.F. Optimum network reconfiguration and DGs sizing with allocation simultaneously by using particle swarm optimization (PSO). Int. J. Eng. Technol. 2014, 6, 773-780.

38. Dahalan, W.M.; Mokhlis, H. Network reconfiguration for loss reduction with distributed generations using PSO. In Proceedings of the 2012 IEEE International Conference on Power and Energy (PECon), Kota Kinabalu, Malaysia, 2-5 December 2012; pp. 823-828. [CrossRef]

39. Tahboub, A.M.; Pandi, V.R.; Zeineldin, H.H. Distribution System Reconfiguration for Annual Energy Loss Reduction Considering Variable Distributed Generation Profiles. IEEE Trans. Power Deliv. 2015, 30, 1677-1685. [CrossRef]

40. Zimmerman, R.D.; Murillo-Sanchez, C.E.; Thomas, R.J. MATPOWER: Steady-State Operations, Planning, and Analysis Tools for Power Systems Research and Education. IEEE Trans. Power Syst. 2011, 26, 12-19. [CrossRef]

41. Ghosh, S.; Sherpa, K.S. An Efficient Method for Load Flow Solution of Radial Distribution Networks. Int. Sch. Sci. Res. Innov. 2008, 2, 2094-2101.

42. Mirjalili, S.; Mirjalili, S.M.; Lewis, A. Grey Wolf Optimizer. Adv. Eng. Softw. 2014, 69, 46-61. [CrossRef]

43. Kennedy, J.; Eberhart, R. Particle swarm optimization. In Proceedings of the ICNN '95-International Conference on Neural Networks, Perth, Australia, 27 November-1 December 1995; Volume 4, pp. 1942-1948. [CrossRef]

(C) 2018 by the authors. Licensee MDPI, Basel, Switzerland. This article is an open access article distributed under the terms and conditions of the Creative Commons Attribution (CC BY) license (http://creativecommons.org/licenses/by/4.0/). 